\title{
The Australian Real-Time Fiscal Database: An Overview with Illustrations of its Use in Analysing Fiscal Policy*
}

by

Kevin Lee ${ }^{\dagger}$, James Morley ${ }^{\dagger \dagger}$, Kalvinder Shields ${ }^{\dagger \dagger}$ and Madeleine Sui-Lay Tan

\begin{abstract}
This paper describes a fiscal database for Australia including measures of government spending, revenue, deficits, debt and various sub-aggregates as initially published and subsequently revised. The data vintages are collated from various sources and provide a comprehensive description of the Australian fiscal environment as experienced in realtime. Methods are described which exploit the richness of the real-time datasets and they are illustrated through an analysis of the extent to which stated fiscal plans are realised in practice and through the estimation of fiscal multipliers which draw a distinction between policy responses and policy initiatives. We find predictable differences between plans and actual fiscal policy and a larger multiplier for policy initiatives than implementation errors.
\end{abstract}

Keywords: Real-time, Australian Database, Revisions, Fiscal Policy, Government Spending, Government Revenues

JEL Classification: C32, D84, E32

\footnotetext{
${ }^{* \dagger}$ University of Nottingham, UK; ${ }^{\dagger \dagger}$ University of Sydney, Australia, ${ }^{\dagger \dagger}$ University of Melbourne, Australia. Version dated September 2019. We are grateful to Renee Fry-McKibbin and an anonymous referee for detailed and constructive comments. Financial support from the ARC (Discovery Grant DP140103029) is gratefully acknowledged. Corresponding author: Kalvinder Shields, Department of Economics, University of Melbourne, Victoria 3010, Australia (k.shields@unimelb.edu.au).
} 


\section{Introduction}

It is now widely recognised that empirical policy analysis can be seriously misleading if it is conducted using the most recent vintage of available data as opposed to the data that was available at the time decisions were actually made. Revisions in data mean that the measurements of historical outcomes published today may differ substantially from the data on which plans were made and so 'real-time' datasets, containing all the vintages of data that were available in the past, are required to fully understand the plans.

A substantial literature has now grown, developing the methods required for the analysis of real-time datasets and their use in prescribing and evaluating policy. ${ }^{1}$ At first these were employed primarily in studies of monetary policy, ${ }^{2}$ but more recently there has been an increased use of real time data in the study of fiscal policy. One reason for this is the recent adoption of formal fiscal policy rules by many governments around the world, as exemplified by the requirements placed on EU member states since 2005 by the Stability and Growth Pact. These typically relate fiscal policy decisions to business cycle conditions and require publication of forward-looking plans for spending and receipts based on early (pre-revision) data. Such institutional frameworks have prompted studies into the extent to which data releases and forecasts are manipulated strategically to fulfill obligations, whether revisions in the underlying data are properly taken into account in plans, and whether plans are actually implemented as intended. Real-time data measures are crucial to such studies. ${ }^{3}$

A second reason for the recent interest in the use of real time data in fiscal policy analysis has been the focus on governments' reactions to the global financial crisis given the constraints imposed on monetary policy by the zero lower bound. This has prompted studies on how actual expenditure relates to planned expenditure at different points in the

\footnotetext{
${ }^{1}$ See, for example, Croushore and Stark (2001) and Croushore and Evans (2006), the October 2009 special issue of the Journal of Business and Economic Statistics.

${ }^{2}$ See Croushore (2011) for a review of many of these and Orphanides and van Norden, 2002, and Garratt et. al., 2009, for specific examples.

${ }^{3}$ Cimadomo (2016) reviews a number of papers in this vein, investigating the time series properties of plans, revisions and outcomes, especially relating to debt and deficits. Other prominent studies include Larch and Salto (2005), Jonung and Larch (2006), Beetsma et al. (2009), and Beetsma et al. (2013).
} 
business cycle and the ways in which expenditure plans are constrained by solvency and other long-horizon considerations. Properly modelling the timing of these interactions has been shown to be key to capturing them empirically. ${ }^{4}$ There has also been renewed interest in the effectiveness of fiscal policy in stimulating the economy and the size of the fiscal multiplier. Estimating the size of the multiplier is not straightforward given the 'fiscal foresight' problem whereby output responses may occur before spending changes are observed because agents react to policy announcements. Again, real-time data measures on actual, planned and expected outcomes are helpful for such studies. ${ }^{5}$

Despite this interest in real time issues, there remains a paucity of datasets that maintain a comprehensive set of real-time observations on fiscal variables over a reasonable time span and frequency appropriate for time series analysis. The real time 'ALFRED' database at the Federal Reserve Bank of St Louis contains the most comprehensive set of fiscal variables with a reasonable time dimension and frequency but covers the US only. The Reserve Bank of Philadelphia's real time database, the OECD's real time database, the ECB-EABCN's EU area-wide real time database, and the recently available Australian Real Time Macroeconomic Database all include some fiscal variables although not in as much detail as that available in ALFRED. For this reason, most empirical studies attempting to look at fiscal policy using real time data have either focused on the use of real time measures of output only or have constructed their own real-time databases for selected fiscal indicators.

This paper describes the construction of a new real-time fiscal dataset for Australia and, focusing on the total expenditure and receipts data only, illustrates the dataset's usefulness first in an analysis of the gap between plans and outcomes and then in estimating the fiscal multiplier. The new dataset is unusual in that it brings together a relatively

\footnotetext{
${ }^{4}$ Golinelli and Momigliano (2006), Bernouth et al. (2008), Beetsma et al (2009), Beetsma and Giuliodori (2010), von Kalckreuth and Wolff (2011), Holm-Hadulla et al. (2012), and Cimadomo (2012), and Corsetti et al (2012) all provide good examples of the estimation of fiscal policy rules using real-time data.

${ }^{5}$ Ramey $(2016,2018)$ provides excellent overviews of this literature, and Cimadomo (2016), Forni and Gambetti (2016), Caggiano et al (2015), Ricco (2016), and Lee et al. (2018) provide useful examples that focus on the use of real-time data.
} 
comprehensive set of real-time measures of government outlays, receipts and debt positions for a single country, and it covers a relatively long time span. The vintages of data are collated from various sources and accommodate multiple methodological changes, providing a comprehensive description of the fiscal environment as experienced by Australian policy-makers at the time decisions were made. Our empirical analyses show how the long time series can be exploited econometrically to identify announcement and implementation effects. As we shall see, we find systematic components in the revisions made to published fiscal data and we find predictable differences between announced plans and actual fiscal policy outcomes. We also find a larger multiplier for spending arising from policy initiatives than policy responses to unexpected events.

The database is available through the University of Melbourne along with a Data Manual describing the sources and definitions of the series in more detail than is possible in this paper; see Lee, Morley, Shields and Tan (2015). However, the description of the database provided in Section 2 below gives an overview of the structure and content of the database and illustrates some of the difficulties in drawing inferences on fiscal policy on the basis of data that is subject to revision. Section 3 then describes the analyses of the expenditure and receipts data to study the gap between planned and realised policies and to use these time series to measure the fiscal multiplier. Section 4 offers some concluding comments.

\section{An Overview of the Australian Real-Time Fiscal Database}

\subsection{Structure and Content}

The Australian Real-Time Fiscal Database includes a total of twelve variables relating to budget outcomes over time plus nine variables describing the evolving state of the government's debt/wealth. The data is collected primarily from the annual Federal Budget which consists of several documents known as Budget Papers, and real-time fiscal data is mainly found in Budget Paper No. $1 .^{6}$ The data vintages match the corresponding budget

\footnotetext{
${ }^{6}$ The Federal government is often referred to a the 'Commonwealth government' in the source materials; we use the terms interchangeably.
} 
publication and are available on an annual basis therefore. The time span of the variables in the data varies, running from Australian Federation in 1901 to the present day for some variables while others are much shorter (e.g. those variables defined following a change in the accounting system in 1998 are only available from the 1999 vintage onwards). The specifics of data availability for each series are provided in Table A1 of the Appendix. Detailed information on the series is provided in the Data Manual.

The variables relating to budget outcomes are set out below:

\section{Table 1: Summary of Budget Data}

\begin{tabular}{|c|c|c|c|}
\hline \multicolumn{2}{|c|}{ Outlays } & \multicolumn{2}{|c|}{ Revenues } \\
\hline $\begin{array}{l}\text { Spending on Goods \& Services } \\
\left.\qquad \begin{array}{cc}\text { Health } \\
\text { of which } \\
\text { Education } \\
\text { Defence }\end{array}\right)\end{array}$ & $\begin{array}{c}E_{t} \\
\left(\begin{array}{c}E_{t}^{H} \\
E_{t}^{E D} \\
E_{t}^{D}\end{array}\right)\end{array}$ & $\begin{array}{l}\text { Income Tax } \\
\quad \text { (or Direct Tax) } \\
\text { Expenditure Tax* } \\
\quad \text { (or Indirect Tax) }\end{array}$ & $\begin{array}{l}\tau_{t}^{Y} \\
\tau_{t}^{E X}\end{array}$ \\
\hline $\begin{array}{l}\text { Spending on Capital Goods } \\
\text { Transfers } \\
\qquad\left(\begin{array}{cc}\text { of which } & \text { Welfare } \\
& \text { Pensions }\end{array}\right)\end{array}$ & $\begin{array}{l}I_{t} \\
W_{t} \\
\left(\begin{array}{c}W_{t}^{S S} \\
W_{t}^{P E N}\end{array}\right)\end{array}$ & Other Revenue & $\tau_{t}^{O}$ \\
\hline Debt Interest Paid & $F_{t}$ & & \\
\hline Total Outlays & $\begin{array}{l}G_{t} \\
=E_{t}+I_{t}+W_{t}+F_{t}\end{array}$ & Total Revenues & $\begin{array}{l}\tau_{t} \\
=\tau_{t}^{Y}+\tau_{t}^{E X}+\tau_{t}^{O}\end{array}$ \\
\hline
\end{tabular}

The evolution of these series over 1947-2014 is described in Figure 1a - 1b. Figure 1a shows the time series of $E_{t}, I_{t}, W_{t}$ and $G_{t}$ as first published after one year (i.e. ${ }_{t+1} G_{t}$, for example, showing the first-release of the realised observations and expressed relative to (first-release) nominal GDP). The time plots show a high degree of constancy in the expenditures relative to output over the period: the 'Great Ratio' of total outlay to output takes an average value of $26 \%$ and lies in the range $24-28 \%$ for most of the sample, suggesting the presence of strong political and social pressures to maintain and control the size of government relative to the economy as a whole. There is a little more variability in the components (transfers, expenditure on goods and services, and capital spend) which 
show some genuine shifts in composition over time and also evidence of breaks due to measurement conventions following the move to an accruals accounting system in 1998-99 as discussed below. Figure $1 \mathrm{~b}$ shows the time series of $\tau_{t}^{Y}, \tau_{t}^{E X}$ and $\tau_{t}$ expressed relative to GDP, again based on first-release data.. The figure illustrates that Income Taxation makes up the largest portion of Total Receipts, contributing around two-thirds of the total tax take over the sample and with this contribution rising a little over time. It also shows the striking constancy of total receipts when expressed relative to total output, suggesting further political and social equilibrating pressures to maintain a broadly balanced budget.

The database also includes series describing the evolving debt/wealth position of the Federal Government. These include:

- Debt, measured in three alternative ways: Net Debt, $D_{t}$; Gross Debt, $D_{t}^{G}$; Public Debt, $D_{t}^{P}$

- Interest payments, measured in three alternative ways: Net Interest Outlays $F_{t}$; Federal Interest Liability $F_{t}^{C}$; and Total Interest Liabilities, $F_{t}^{L}$; and

- Wealth, again measured by three complementary variables: Net Worth $V_{t}$; Net Operating Balance $V_{t}^{O}$; and Net Financial Worth $V_{t}^{F}$.

The existence of the various different measures of similar concepts reflects the complexity of government accounting standards and practices. 'Public debt' refers to the stock of debt held by Federal government only while 'Gross Debt' refers to debt held by both Federal and State governments. 'Net debt' is a measure that is used as a standard to compare debt positions across different countries and again refers to the Federal government position only. The interest payment variables are similarly related: 'Federal interest liability' refers to the interest owing on the stock of public debt whereas 'total interest liability' refers to the interest due on the stock of debt held by both the Federal and State governments. The 'net worth' and 'net financial worth' variables reflect the wealth position of the Federal government, the latter focusing on that part held in the form of financial assets and liabilities. 'Net operating balance' refers to the viability of the government position, showing the difference between total revenue and total expenditure in 
the operating statement. More complete details on the coverage of the data is provided in Table A1 of the Appendix and in the Database Manual.

We also provide data on three important constructed variables:

- The Public Sector Financial Surplus (or 'Cash Balance'), $S_{t}=\tau_{t}-G_{t}$, showing the excess of receipts over total outlays;

- The Primary Surplus $S_{t}^{P}=\tau_{t}-\left(G_{t}-F_{t}\right)$ showing the financial surplus abstracting from interest payments; and

- The Stock-Flow Residual $\nu_{t}=D_{t}-\left(D_{t-1}-S_{t}\right)$ which aims to reconcile the budget balance sheet outcomes with the evolving debt position.

The first two of these are the focus of much policy discussion reflecting the government's spending decisions relative to its ability to finance these within the year. The stockflow residual $\nu_{t}$ is important in understanding government's financial constraints over the longer term. Specifically, we note that, if changes in liabilities are the result of "above-theline" budgetary operations only, then debt in $t$ would equal $\left(1+r_{t}\right) D_{t-1}+S_{t}^{P}=D_{t-1}+S_{t}$. In practice, however, debt liabilities are influenced by a whole range of additional factors, including privatisation proceeds, off-budget operations, gains and losses on (below-theline) financial operations; valuation changes due to exchange rate movements and central bank deficit financing, such as purchases of government debt (seigniorage). These values can be very large at times and can therefore, have a considerable impact on government's plans over the longer term.

The variables in the database are presented in a common format. There is an Excel workbook for each of the variables containing a summary of the details of the data (source, definition, etc.) on the first sheet and the raw data in a second sheet. If we denote a variable $Z$ at time $t-s$ by $Z_{t-s}$ and the measure of this magnitude as published in time $t$ by ${ }_{t} Z_{t-s}$, then the time- $t$ vintage of data typically includes the observations ${ }_{t} Z_{1},{ }_{t} Z_{2}, \ldots$, ${ }_{t} Z_{t}$. The observation ${ }_{t} Z_{t-1}$ shows the first-release of the measure of $Z_{t-1}$, taking into account that there is usually a one year delay in the release of data, and the observations ${ }_{t} Z_{t-s} s=2, \ldots$ shows the time $t$ measures of past values accommodating any revisions. 
The observation ${ }_{t} Z_{t}$ shows the value of the variable that the government plans to spend in year $t$ as published in year $t$. The raw data are in the form of "data triangles" where each column of data relates to a data vintage so that the successive columns grow longer each period to give a triangular shape to the dataset. The rows show the published measure for the same observation at different vintages so the revisions to a particular observation can be tracked by looking horizontally across the spreadsheet.

\subsection{Unrealised Plans, Methodological Changes and Revisions in Australian Fiscal Data}

The various vintages of data show how the measurement of a variable might change over time. These are often best expressed in proportional terms and, in what follows, we use upper case letters to denote the value of a variable and lower case to denote its $\operatorname{logarithm}$; i.e. $z_{t}=\log \left(Z_{t}\right)$. Our real time dataset includes measures of the planned values of variables (e.g. ${ }_{t} g_{t}$ ) as well as the subsequent measures of the actual value of the variable $\left({ }_{t+s} g_{t}, s=1,2, \ldots\right)$. Comparison with the first-release data ${ }_{t+1} g_{t}$ shows the extent to which the stated plans were or were not realised, but changes in the measures of the actual outcomes can also occur, either through 'revisions', based on the arrival of new information on the series, or through a change in the way a concept is conceived; i.e. involving a 'methodological' or 'definitional' change.

Methodological changes produce once-and-for-all shifts in a series, they typically occur only periodically and their timing and nature are well-documented. This means that their effect can usually be readily taken into account by a simple scaling of the pre-change data by some additive or multiplicative factor. Fiscal data is particularly vulnerable to methodological changes because public spending can have multiple purposes (for example, spending on health or education involves an element of investment as well as immediate

consumption). Further methodological changes can arise because the role and scope of government changes over time, because responsibility can switch across different agencies (State versus Federal government for example), and because there is often a political dimension to fiscal decisions.

Methodological changes that had particularly wide-ranging impacts on fiscal data in- 
clude:

- The 1910 and 1966 currency changes: from the British pound to the Australian pound in 1910, and to the Australian dollar in 1966, impacting on the valuation of domestic and foreign assets, for example;

- The 1974 accounting framework change: when the 1974-75 Budget switched from an accounting classification to a functional classification, aligning expenditures with function rather than departmental portfolios;

- The 1994 accounting year change: when the Budget release day was moved from the first quarter of the fiscal year to mid-May;

- The 1996/97 methodological changes: when net advances are excluded from the reported measure of outlays;

- The 1998/99 legal reform: the Charter of Budget Honesty Act 1998 introduced a mid-year update to the budget, a move from a cash accounting to an accrual accounting system and, in 1999, the reporting of new accrual Government Financial Statistics (GFS) variables in the budget; and

- The 2008 reporting standards reform: the introduction of a new accounting system which harmonised reporting standards used previously. ${ }^{7}$

It is well understood that methodological changes of this sort will effect measurement. But data "revisions" can also be substantial because, for example, revenue collection, auditing of accounts and collating information on spending across government departments are all time consuming processes. Published data often supplements raw source data with 'modelled' data that anticipates the arrival of additional and/or more reliable data and so revisions in measures of realised fiscal magnitudes can continue for some time.

Figures $2 \mathrm{a}$ and $2 \mathrm{~b}$ illustrate some of the effects of data definitions and revisions in the Australian fiscal data. Figure 2a shows the measure of the surplus in 1948/49 as reported

${ }^{7}$ See full explanation at ABS or summary of differences here:
http://dro.deakin.edu.au/eserv/DU:30077129/wines-australiangovernment-post-2015.pdf


first in 1949/50 and then subsequently in publications dated through to 2015/16; i.e. ${ }_{t} S_{1948 / 49}^{P}, t=1949 / 50, \ldots, 2015 / 16 .{ }^{8}$ The measure refers to the surplus in a given year but it experiences a number of clear and distinct changes, sometimes more than fifty years later, to reflect the methodological changes flagged above. Indeed, the measure of the 1948/49 surplus switches from negative to positive in 1996, highlighting the insights that can be lost in working only with final-vintage datasets. The Figure also shows measures of the primary balance in five later years - in 1958/59, 1968/69, 1978/79, 1988/89 and 1998/99 - again as first-released and then in subsequent publications. These measures also undergo considerable shifts to reflect the methodological changes mentioned above. Of course, the plots also capture the (more modest) effects of data revisions which typically show up as adjustments in the measures over a small number of years after the firstrelease. ${ }^{9}$

The measures in Figure 2a are in nominal terms and so the size of the surpluses, and methodological changes involved, are larger at later dates (and particularly after the seventies) simply reflecting rising prices. Figure $2 \mathrm{~b}$ considers the real surpluses therefore, expressing the series as a ratio to the first-release measures of nominal output. The break points associated with methodological changes are, of course still apparent and, in comparison with Figure 2a, there is additional time-variation in the series introduced through updates on the output data. It is interesting to see that, having scaled by output level, the sizes of the methodological shifts now appear larger for earlier dates than for later ones, suggesting that it is less disruptive to update observations from the near past than the distant past when methodological changes are introduced. These measurement issues potentially introduce systematic features into the data therefore which are difficult to overcome but which cannot be ignored in empirical work. One approach to the problem is to conduct the analysis on transformed data (e.g. working with differences or even differences in differences), but our recommendation is to deal with the effects of methodological changes on a case-by-case basis prior to any analysis. This has the

\footnotetext{
${ }^{8}$ The $1948 / 49$ statistic was not reported in the $1962 / 63,1963 / 64$ or $1964 / 65$ publications and so the statistics plotted for these dates are assumed unchanged from those published in 1961/62.

${ }^{9}$ As it turns out, revisions in the primary balance statistics are driven primarily by revisions in data on receipts, with government spending figures relatively stable after first release.
} 
advantage that adjustments to the data can take into account any known information relevant to the change while leaving the interpretation of the series and any relationships between series unaltered. ${ }^{10}$

\section{Using the Real-Time Fiscal Data: An Analysis of Total Outlay and Total Receipts}

The importance of the use of real-time data is best conveyed by looking at specific issues and in this section we make use of the real-time data on total outlays and total receipts to examine (i) whether the government's fiscal plans are realised and, to the extent that they are not, whether there are any systematic patterns in the gap between plans and outcomes; and (ii) whether the information on plans and outcomes provides insights on the usefulness of fiscal policy in demand management.

These are important questions. If the government announces in year $t$ that it plans to spend ${ }_{t} g_{t}$ but it turns out that spending is ${ }_{t+1} g_{t} \neq{ }_{t} g_{t}$ and that this gap is systematically related to information that was known at $t$, then either there are information rigidities or problems in implementing plans that cause government to be systematically but unintentionally over- or under-optimistic, or government is choosing to make announcements on commitments that it knows it will not fulfill. The same applies for government announcements and realisations of revenues, ${ }_{t} \tau_{t}$ and for measures of the overall financial surplus, ${ }_{t} S_{t}$, and the interaction between these is also potentially informative on motives: for example, if government spending and overall deficit turn out to be systematically higher than announced, the government is simply spending beyond its stated intentions; if spending is systematically higher than announced but the overall deficit turns out as planned, the government has expanded the size of government beyond its announcements but is balancing the books as it does so.

The second question relates to the size of the fiscal multiplier. As noted earlier, this has attracted considerable recent attention and several studies have employed VAR models to isolate government spending shocks and to trace out their dynamic effects on output

\footnotetext{
${ }^{10}$ See the discussion in Garratt et al (2008) and Clements and Galvao (2013) on the pros and cons of using levels or differences in real-time measures of output when estimating the output gap.
} 
to estimate the size of the multiplier. However, these rely on controversial identifying assumptions and are potentially undermined by the 'fiscal foresight' problem. This problem arises because it is difficult to quantify the output effects of agents' reactions to spending plans that have been announced but not yet implemented if the investigator uses output and spending data alone. Lee, Morley, Ong and Shields (2018) [LMOS] address these difficulties in a VAR analysis of the US multiplier using data on spending plans alongside data on actual spending. This work finds that the multiplier effect of spending undertaken in reaction to adverse circumstances ('policy responses') is approximately half the size of the multiplier effect of planned spending ('policy initiatives'). This idea has important implications for macroeconomic policy and can only be examined empirically employing real-time fiscal data of the sort we have collated here for Australia.

\subsection{Australian Fiscal Plans and Outcomes, 1957-2015}

An analysis of the interplay between spending plans and outcomes can be conducted in a simple VAR framework, as exemplified by:

$$
\begin{aligned}
\mathbf{G}_{t} & =\left(\begin{array}{c}
{ }_{t} g_{t-2}-{ }_{t-1} g_{t-2} \\
{ }_{t} g_{t-1}-{ }_{t-1} g_{t-1} \\
{ }_{t} g_{t}-{ }_{t} g_{t-1}
\end{array}\right)=\mathbf{A}_{0}+\mathbf{A}_{1}\left(\begin{array}{c}
{ }_{t-1} g_{t-3}-{ }_{t-2} g_{t-3} \\
{ }_{t-1} g_{t-2}-{ }_{t-2} g_{t-2} \\
{ }_{t-1} g_{t-1}-{ }_{t-1} g_{t-2}
\end{array}\right)+\left(\begin{array}{c}
\varepsilon_{1 t} \\
\varepsilon_{2 t} \\
\varepsilon_{3 t}
\end{array}\right) \\
& =\mathbf{A}_{0}+\mathbf{A}_{1} \mathbf{G}_{t-1}+\boldsymbol{\varepsilon}_{t}
\end{aligned}
$$

Here, ${ }_{t} g_{t-2}-{ }_{t-1} g_{t-2}$ shows the revision in the measures of spending in time $t-2$ as revealed between the publications in $t-1$ and $t$. The coefficients in the first rows of the $3 \times 1$ vector $\mathbf{A}_{0}$ and the $3 \times 3$ parameter matrix $\mathbf{A}_{1}$ will be non-zero if there are systematic elements in these revisions (reflecting deficiencies in the measurement process) and $\varepsilon_{1 t}$ represents the unsystematic "measurement error". The variable ${ }_{t} g_{t-1}-{ }_{t-1} g_{t-1}$ shows the gap between the actual government spending outcome in time $t-1$ and the original planned spending level. The extent to which this over- or under-predicts spending is captured by the second element of $\mathbf{A}_{0}$ and on the known information captured by the elements in the second row of $\mathbf{A}_{1}$. These parameters provide an indication of the extent to which governments are, inadvertently or intentionally, systematically over- or under-optimistic then, while 
$\varepsilon_{2 t}$ represents the unsystematic "implementation error". The third row of $\mathbf{G}_{t}$ contains the planned growth in spending in time $t,{ }_{t} g_{t}-{ }_{t} g_{t-1}$, as announced in the time- $t$ budget and the $\varepsilon_{3 t}$ represents news arriving in time- $t$ on planned spending in $t$. If revisions and unplanned spending are stationary (whether systematic or not) and if actual government spending is driven by a stochastic trend, ${ }^{11}$ then the three series in $\mathbf{G}_{t}$ - which can all be written as sums of revisions, actual growth and unplanned spending - are all stationary and the VAR model of (3.1) is appropriate.

An examination of the hypothesis that the government's announced plans for spending are realised on average - taking measurement issues into account and with no systematic element in unplanned spending - involves testing whether $E\left({ }_{t} g_{t-1}\right)={ }_{t-1} g_{t-1}$ in (3.1); i.e. given by a test of

$$
H_{0}: a_{21}=a_{22}=a_{23}=0 \text { in } \mathbf{A}_{1} \text {. }
$$

so that unplanned spending depends only on the random "implementation error". An equivalent test can also be conducted to test whether there are systematic elements in the revisions between the first- and second-release of the policy measures, testing

$$
H_{0}: a_{11}=a_{12}=a_{13}=0 \text { in } \mathbf{A}_{1} .
$$

Of course, similar exercises can be conducted for the three measures of receipts and for the three measures of the financial surplus to judge whether government's fiscal plans are realised, whether there are any systematic patterns in the gap between plans and outcomes, and how these gaps, if they exist, effect the public finances.

Figures $3 a$ plots the three spending series discussed above for $G_{t}$ as published in successive years; namely, ${ }_{t} G_{t},{ }_{t+1} G_{t}$ and ${ }_{t+2} G_{t}$. The plots show that, broadly speaking, the series move one-for-one over the long term but with some substantial discrepancies from this pattern over some periods. Figures $3 \mathrm{~b}$ and $3 \mathrm{c}$ make the same point for receipts and the primary surplus, with the latter - being based on both series - showing the most striking differences between the measures. Table 2 provides some basic summary statistics

\footnotetext{
${ }^{11}$ This will be the case if, for example, output is driven by a stochastic productivity shock and a constant Great Ratio is maintained between spending and output.
} 
for the series showing, for example, that the actual annual growth in spending averaged $3.7 \%$ over the period 1957-2015 and published spending growth plans averaged at 2.5\%. On average, actual spending outpaced planned spending then but with standard errors of the series at around $4 \%$, the simple gap between these averages is not statistically significant.

Table 2: Summary Statistics for Selected Policy Variables, 1957-2015

\begin{tabular}{|c|c|c|c|c|c|}
\hline Revision & $\begin{array}{l}\text { Mean } \\
\text { (St.Dev.) }\end{array}$ & Actual Growth & $\begin{array}{c}\text { Mean } \\
\text { (St.Dev.) }\end{array}$ & Planned Growth & $\begin{array}{c}\text { Mean } \\
\text { (St.Dev.) }\end{array}$ \\
\hline${ }_{t} g_{t-2}-{ }_{t-1} g_{t-2}$ & $\begin{array}{c}-0.0028 \\
(0.0103)\end{array}$ & ${ }_{t} g_{t-1}-{ }_{t-1} g_{t-2}$ & $\begin{array}{l}0.0368 \\
(0.0442)\end{array}$ & ${ }_{t} g_{t}-{ }_{t} g_{t-1}$ & $\begin{array}{l}0.0251 \\
(0.0375)\end{array}$ \\
\hline${ }_{t} \tau_{t-2}-{ }_{t-1} \tau_{t-2}$ & $\begin{array}{c}-0.0456 \\
(0.0381)\end{array}$ & ${ }_{t} \tau_{t-1}-{ }_{t-1} \tau_{t-2}$ & $\begin{array}{l}0.0358 \\
(0.0561)\end{array}$ & ${ }_{t} \tau_{t}-{ }_{t} \tau_{t-1}$ & $\begin{array}{c}-0.0111 \\
(0.0516)\end{array}$ \\
\hline${ }_{t} S_{t-2}^{p}-{ }_{t-1} S_{t-2}^{p}$ & $\begin{array}{c}-69.094 \\
(61.783)\end{array}$ & ${ }_{t} S_{t-1}^{p}-{ }_{t-1} S_{t-2}^{p}$ & $\begin{array}{l}-4.890 \\
(129.606)\end{array}$ & ${ }_{t} S_{t}^{p}-{ }_{t} S_{t-1}^{p}$ & $\begin{array}{l}-54.548 \\
(112.936)\end{array}$ \\
\hline
\end{tabular}

Notes: $g_{t}, \tau_{t}$ and $S_{t}^{p}$ refer to government spending, receipts and primary budget surplus respectively.

However, a more thorough examination of the data can be obtained through estimated models of the sort described in (3.1). Unit root tests applied to the various individual spending series, and to the receipts and output data establishes that these series are all individually difference-stationary so that the VAR modelling approach presented in (3.4) is appropriate, although we found that a VAR order 3 is necessary to eliminate any residual serial correlation. ${ }^{12}$ Table 3 summarises the outcome of the variable deletion tests where, in practice, the tests investigates the joint insignificance of nine parameters given that our VAR is third-order. The tests are conducted separately on the spending, receipts and surplus data in turn. In (3.2), the test is whether the revisions between the first and second releases of the measures are uncorrelated with past information and simply reflect random 'measurement error'; and in (3.3), the test is whether the gaps between the planned policy and the outcomes are random 'implementation errors'.

\footnotetext{
${ }^{12}$ Results for these various tests are available from the authors on request.
} 


\section{Table 3: Tests of Whether Data Revisions and Unplanned Policy Outcomes are Unsystematic}

\begin{tabular}{llllll}
\hline Revision & LM & (p-value) & Unplanned Policy & LM & (p-value) \\
\hline${ }_{t} g_{t-2}-{ }_{t-1} g_{t-2}$ & 11.96 & 0.22 & ${ }_{t} g_{t-1}-{ }_{t-1} g_{t-1}$ & 14.80 & 0.10 \\
${ }_{t} \tau_{t-2}-{ }_{t-1} \tau_{t-2}$ & 51.27 & 0.00 & ${ }_{t} \tau_{t-1}-{ }_{t-1} \tau_{t-1}$ & 36.13 & 0.01 \\
${ }_{t} S_{t-2}-{ }_{t-1} S_{t-2}$ & 47.54 & 0.00 & ${ }_{t} S_{t-1}-{ }_{t-1} S_{t-1}$ & 22.51 & 0.01 \\
\hline
\end{tabular}

Note: Statistics refer to LM tests of (3.2) and (3.3). Statistics are compared to a $\chi^{2}$-distribution with 9 degrees of freedom. See also Notes to Table 2.

On revisions, the results reject the view that 'measurement error' is random for receipts and surpluses, with significance established at the $1 \%$ level, but show no systematic patterns in spending revisions. Of course, the observed systematic downward revisions in receipts (and hence surpluses) could reflect a desire of governments to err on the side of reporting that they have behaved more prudently than they actually have. But it could also reflect systematic failings in the measurement process. As discussed earlier, collating the appropriate information takes time and first releases often use 'modelled data' until more reliable data become available. It is sometimes preferable to publish measures of a variable obtained through best practice measurement techniques even if that means there is a systematic pattern in subsequent revisions. ${ }^{13}$

The tests show similar results for unplanned policy, with the gaps between announced plans and actual outcomes being systematically related to past information, again at the $1 \%$ significance level for receipts and surpluses and at the $10 \%$ level for spending. Once more, the results could arise through an intentional misrepresentation of plans or simply because government is unable to control its spending and receipts (even though this is in such a way that is entirely predictable when the plans are announced). It is not possible to distinguish the causal mechanisms without further information, including the nature

\footnotetext{
${ }^{13}$ The users of the data can then deal with the predictable element of the revision as they see fit. The alternative is for the government to eliminate the systematic element of revisions prior to publication but this may involve a mechanical adjustment that users of the data would prefer not to have to unravel before their own analysis.
} 
of the incentives faced by government in releasing fiscal information, ${ }^{14}$ but the results clearly establish the presence of significant biases in both revisions and unplanned policy outcomes.

\subsection{Estimating the Fiscal Multiplier}

The information on plans and outcomes in our database can also be used to investigate the effectiveness of fiscal policy in demand management through estimation of the fiscal spending multiplier, as in LMOS. The modelling again focuses on the time series characterisation of the spending measures in (3.1) but now considers the interplay between spending, receipts and output in the extended model: ${ }^{15}$

$$
\left(\begin{array}{c}
{ }_{t} g_{t-1}-{ }_{t-1} g_{t-1} \\
{ }_{t} \tau_{t-1}-{ }_{t-1} \tau_{t-2} \\
{ }_{t} y_{t-1}-{ }_{t-1} y_{t-2} \\
{ }_{t} g_{t}-{ }_{t} g_{t-1}
\end{array}\right)=\mathbf{A}_{0}+\mathbf{A}_{1}\left(\begin{array}{c}
{ }_{t-1} g_{t-2}-{ }_{t-2} g_{t-2} \\
{ }_{t-1} \tau_{t-2}-{ }_{t-2} \tau_{t-3} \\
{ }_{t-1} y_{t-2}-{ }_{t-2} y_{t-3} \\
{ }_{t-1} g_{t-1}-{ }_{t-1} g_{t-2}
\end{array}\right)+\boldsymbol{\alpha}\left(\begin{array}{c}
{ }_{t-1} g_{t-2}-{ }_{t-1} y_{t-2} \\
{ }_{t-1} \tau_{t-2}-{ }_{t-1} y_{t-2}
\end{array}\right)+\left(\begin{array}{c}
\varepsilon_{2 t} \\
\varepsilon_{3 t} \\
\varepsilon_{4 t} \\
\varepsilon_{5 t}
\end{array}\right)
$$

The measures ${ }_{t} \tau_{t-1}$ and ${ }_{t} y_{t-1}$ are, respectively, the (logarithms of the) actual level of government receipts received and the actual level of output observed during year $t-1$ as reported in the fiscal budget published in year $t$. The model of (3.1) is extended in (3.4) to include growth in receipts and growth in outputs as part of the VAR plus two additional equilibrating terms: ${ }_{t-1} g_{t-2}-{ }_{t-1} y_{t-2}$ capturing any pressures to return to a constant 'Great Ratio' between spending and output; and ${ }_{t-1} \tau_{t-2}-{ }_{t-1} y_{t-2}$ which, if there are pressures to establish a constant Great Ratio, implies that equilibrating pressures are also experienced to establish a balanced budget. The data suggests that the inclusion of these terms is appropriate too: Figure 4 shows that spending-to-output and receipts-to-

\footnotetext{
${ }^{14}$ For example, there are incentives for some euro area member countries to publish optimistic initial estimates of debt and deficits and/or forecasts of plans that would reduce the future budget balance since these effect the nature of sanctions and/or fiscal adjustments agreed under the Growth and Stability Pact. Obviously these incentives would not apply to Australia. We are grateful to a referee for highlighting this point.

${ }^{15}$ The earlier finding that there are no systematic patterns in the spending revision, ${ }_{t} g_{t-2}-{ }_{t-1} g_{t-2}$, means we can drop this variable from the analysis.
} 
output ratios are remarkably constant over time and unit root tests show they are indeed stationary.

Estimates of the fiscal spending multiplier are obtained by examining the effects of a shock to government spending, expressing the accumulated addition to output as a ratio to the accumulated increase in spending. These effects can be obtained from an impulse response analysis of the estimated model in (3.4). LMOS highlight two issues that complicate this analysis but which provide new insights when we employ data on planned spending alongside the actual outcomes. The first issue relates to defining the appropriate impulse in the analysis and can be explained by noting that the model in (3.4) can be rewritten as the following VAR in levels:

$$
\begin{aligned}
\mathbf{Z}_{t} & =\left(\begin{array}{c}
{ }_{t} g_{t-1} \\
{ }_{t} \tau_{t-1} \\
{ }_{t} y_{t-1} \\
{ }_{t} g_{t}
\end{array}\right)=\mathbf{B}_{0}+\mathbf{B}_{1}\left(\begin{array}{c}
{ }_{t-1} g_{t-2} \\
{ }_{t-1} \tau_{t-2} \\
{ }_{t-1} y_{t-2} \\
{ }_{t-1} g_{t-1}
\end{array}\right)+\mathbf{B}_{2}\left(\begin{array}{c}
{ }_{t-2} g_{t-3} \\
{ }_{t-2} \tau_{t-3} \\
{ }_{t-2} y_{t-3} \\
{ }_{t-2} g_{t-2}
\end{array}\right)+\left(\begin{array}{c}
e_{2 t} \\
e_{3 t} \\
e_{4 t} \\
e_{5 t}
\end{array}\right) \\
& =\mathbf{B}_{0}+\mathbf{B}_{1} \mathbf{Z}_{t-1}+\mathbf{B}_{2} \mathbf{Z}_{t-2}+\mathbf{e}_{t}
\end{aligned}
$$

where the B's are transformations of the parameters in A, restricted to retain the property of (3.1) that the three series move together one-for-one in the long run, and where $\mathbf{e}_{t}=\left(\varepsilon_{2 t}\right.$, $\left.\varepsilon_{3 t}, \varepsilon_{4 t}, \varepsilon_{2 t}+\varepsilon_{5 t}\right)^{\prime}$ - i.e. an accumulation of the implementation shock and news on time$t$ plans for the spending variable ${ }_{t} g_{t}$. A Generalised Impulse Response analysis can be used to trace out the effects of a typical time- $t$ shock to $\mathbf{Z}_{t}$ which, of course, includes the responses of ${ }_{t} g_{t-1}$ and ${ }_{t} y_{t-1}$. But if our interest is on the effect of time-t news on spending and output from time- $t$ onwards, we are really interested in the effects of a shock to the one-step-ahead forecast $\widehat{\mathbf{Z}}_{t}=E\left[\mathbf{Z}_{t+1} \mid \Omega_{t}\right]$ based on information at time $t, \Omega_{t}$, which has the representation

$$
\widehat{\mathbf{Z}}_{t}=\left(\mathbf{B}_{0}+\mathbf{B}_{0} \mathbf{B}_{1}\right)+\left(\mathbf{B}_{1} \mathbf{B}_{1}+\mathbf{B}_{2}\right) \mathbf{Z}_{t-1}+\left(\mathbf{B}_{1} \mathbf{B}_{2}\right) \mathbf{Z}_{t-2}+\widetilde{\mathbf{e}}_{t}
$$

where now $\widetilde{\mathbf{e}}_{t}=\mathbf{B}_{1} \mathbf{e}_{t}$ is the news arriving at time $t$ on spending that will actually take place in $t$. An impulse response analysis based on (3.6) is likely to be quite different to an impulse response analysis of (3.5). For example, if ${ }_{t} g_{t}$ has good forecasting power for 
$E\left[{ }_{t+1} g_{t} \mid \Omega_{t}\right]$, then strong weight will be given - via $\mathbf{B}_{1}$ - to news on planned spending $e_{5 t}$ in the impulse response analysis of a shock to $E\left[{ }_{t+1} g_{t} \mid \Omega_{t}\right]$ using (3.6). This news is likely to receive less weight in the impulse response analysis of a shock to ${ }_{t} g_{t-1}$ through (3.5) which is more backward-looking and likely to be dominated by the $e_{2 t}$.

The second issue raised in LMOS further explores this idea through a decomposition of the $\mathbf{e}_{t}$ into four orthogonal shocks $v_{1 t}, \ldots, v_{4 t}$ based on a number of identifying restrictions. In the context of (3.6), it might be assumed that the policy variables ${ }_{t} g_{t-1},{ }_{t} \tau_{t-1}$, and ${ }_{t} g_{t}$ are determined in that order, and that the system is driven by three transitory shocks $v_{1 t}, \ldots, v_{3 t}$ and a single stochastic trend $v_{4 t}$ driving the variables in the long-run. The timing assumptions on the policy variables means that $v_{1 t}$ and $v_{2 t}$ can be interpreted as 'spending policy response' and 'receipts response' shocks respectively, and $v_{3 t}$ can be interpreted as a 'spending policy initiative' shock. This decomposition can be applied to the impulse responses and to the estimated spending multipliers and LMOS find that, in the US, the multiplier effects of forward-looking policy initiatives are considerably higher than the overall multiplier effects based on policy responses and policy initiatives taken together. Of course, it is interesting to find whether a similar conclusion is obtained with the Australian data.

Figures 5a and 5b report two Generalised Impulse Response (GIR) functions obtained using this estimated model. Figure 5a provides a 'standard' GIR showing the effects of a system-wide $\mathbf{e}_{t}$ shock to $\mathbf{Z}_{t}$ - as captured by (3.5) - that causes ${ }_{t} g_{t-1}$ to rise by $1 \%$ on impact. This shock is also associated with planned spending ${ }_{t} g_{t}$ rising on impact (although not by as much) and with a first-release measure of output falling. The subsequent dynamic response has the spending level falling monotonically and shows that it takes as long as a decade for the effects of the shock to work themselves out. The new equilibrium position re-establishes the Great Ratio with spending and output converging to the same level around $1 \%$ lower than would have been observed in the absence of the shock. In contrast, Figure $5 \mathrm{~b}$ traces the effects of a system-wide $\widetilde{\mathbf{e}}_{t}=\mathbf{B}_{1} \mathbf{e}_{t}$ shock to to $\widehat{\mathbf{Z}}_{t}$ - as captured by the four-variable version of (3.6) -which cause the one-step ahead forecast $E\left[{ }_{t+1} g_{t} \mid \Omega_{t}\right]$ to rise by $1 \%$ on impact. Here output rises on impact and the subsequent dynamic response has spending and output rising for three/four years, then falling to 
around $0.4 \%$ higher than would be achieved in the absence of the shock after about a decade and finally settling at a permanent $0.15 \%$ increase. If we are interested in the multiplier effects of time- $t$ innovations on spending and output at time- $t$ and beyond, it is the latter response that is relevant.

The two GIRs illustrate the effects of two different types of shock and highlight different features of the interplay between planned and actual spending and output. As noted earlier, one interpretation of the figures is that Figure 5a, which is dominated by the effects of the shock to ${ }_{t} g_{t-1}$, shows the effects of an unanticipated adverse macroeconomic event causing output to fall and initiating an offsetting policy response, while Figure 5b is dominated by the effects of the shock to ${ }_{t} g_{t}$, which might better reflect the effects of productivity-based improvements in output and associated proactive increase in spending through policy initiatives. This idea can be pursued through the orthogonalisation of the $\mathbf{e}_{t}$ shocks mentioned above. Here, the estimated model is re-cast in a form that assumes the presence of a permanent productivity shock $v_{4 t}$ and the timed sequence of events identifying the spending implementation shock $v_{1 t}$, the receipts implementation shock $v_{2 t}$ and the spending initiative shock $v_{3 t}$. The spending implementation shock and the spending initiative shock identified in this way are plotted in Figure 6 and the impulse responses associated with these two innovations - separately and in total - are plotted in Figure 7. The response to the total shock replicates the shape of the response in Figure $5 \mathrm{~b}$ and follows closely the response to $v_{3 t}$ alone showing that this response is indeed driven primarily by the initiative shock rather than the implementation shock.

Figure 8 shows again the effects of the joint shock but traces out the corresponding output effect too. Figure 9 translates these effects into the measure of the multiplier, based on the ratio of the accumulated output effect divided by the accumulated spending effect; that is, the integral of the output boost - showing the present value of all future output gains - expressed relative to the integral of government spending showing the present value of all the future government spending initiated by the policy shock. ${ }^{16}$ Since the model

\footnotetext{
${ }^{16}$ This measure of the multiplier emphasises the long term consequences of a fiscal policy shock and is more appropriate than, for example, the measure based on the peak output response relative to the initial spending impact sometimes reported in the literature. See Ramey (2018) for further discussion.
} 
is estimated in logarithms, the accumulated effect is then rescaled by the sample mean of output over spending to convert the elasticities into a multiplier expressed in dollar units. The figure shows a total multiplier of effect of around 1.41 over the first six years, ultimately flattening out to 1.72 (at which point the shock has no further impact on output relative to spending). The interpretation is that an unexpected change in policy that raises government spending by $\$ 1$ over the life of a policy is estimated to increase output by $\$ 1.72$ over the same time frame. The multiplier effect is still larger, reaching 1.79 at the long horizon, if we focus only on the effects of unexpected policy initiatives, abstracting from the output effect of implementation shocks (whereby spending is higher than had been originally planned). This means that the long run impact of implementation shocks are actually negative.

The total multiplier estimate is relatively large; as Ramey (2016) notes, estimates of multipliers found in the literature typically lie in the range $[0.6,1.5]$ although larger estimates are not unusual. Some part of the variation in reported estimates reflects differences in the way multipliers are modelled and defined. More structural models obtain estimates of the multiplier as the outcome of the interplay of many behavioural equations (as in Li and Spencer's (2015) Australian DSGE model who report a multiplier that peaks at 1.26 after one year) or as implied by specific relations (as in Makin and Narayan's (2011) analysis of the offset between Australian public and private savings, interpreted to imply a small or near-zero multiplier). The derived multipliers are sensitive to the analysis of the specific behavioural relations or the interplay between them. Our VAR-based approach to measuring the multiplier focuses on the evolution of output and government spending in response to an unanticipated fiscal shock summarising the complexity of the macroeconomic response with the reduced form VAR. But even among VAR-based models, some multipliers reported in the literature accumulate the discounted values of the output response to a policy shock expressed relative to the accumulated discounted spending responses, others truncate the response horizon and still others focus on specific points of the responses (e.g. the peak response). Our multiplier is based on the accumulated undiscounted response without truncation and this might result in a higher estimated value than some measures. 
Of course the range of multiplier estimates will also reflect structural differences across countries (with fiscal stimuli having greater output effects in countries with larger real, nominal and informational rigidities, for example), the political and economic pressures influencing fiscal decisions over time and the way in which these are captured in the model. Our underlying model explicitly acknowledges the unit root and cointegrating properties of the data. The shocks to the system therefore allow spending, receipts and output to be permanently higher than they would be in the absence of the shock, with the cointegrating relations ensuring that the spending-to-output Great Ratio and a balanced budget is eventually re-established. Having assumed that there is a single stochastic trend driving the system and having therefore identified our spending and receipt shocks as having transitory effects, the size of the multiplier is influenced not only by the output effect of a fiscal stimulus but also by the speed with which these long-run relations are re-established. In contrast, most of the multiplier estimates found in the literature are based on models estimated on (log) levels. In principle, these allow for unit roots and cointegration among the variables but in practice it means that all shocks are assumed to have transitory effects (even if these are possibly quite persistent). This can result in unrealistically rapid or unrealistically slow adjustment if the omitted long-run relations exert weak or strong equilibrating pressures. In the case of Australia, we find a very protracted transition to equilibrium, lasting up to twenty years, ${ }^{17}$ and this is likely to compound the direct output effects of individual fiscal stimuli and may provide another explanation for our relatively large estimated multiplier.

\section{Concluding Comments}

The Australian Real-Time Fiscal Database provides an invaluable source of information on government spending and government receipts - in total and split into their constituent parts - and on its debt position, providing information on plans as well as outcomes, as published in real time. The data is complex and this paper provides an overview of the complexity, illustrating the nature of the methodological changes and revisions embedded

\footnotetext{
${ }^{17}$ This may reflect the scepticism expressed by Dizioli et al. (2017), for example, on the extent of government budgetary discipline observed in practice.
} 
within it. But the data is also extremely informative and necessary if decision-making is to be properly evaluated taking into account the information available at the time decisions were made. The empirical analyses of the paper illustrate the point, highlighting the predictability of the gaps between announced plans and realised outcomes and showing the importance of distinguishing between policy responses and policy initiatives in estimating the fiscal multiplier.

\section{References}

Beetsma, R., B. Bluhm, M. Giuliodori and P. Wierts, (2012) "From Budgetary Forecasts to Ex Post Fiscal Data: Exploring the evolution of fiscal forecast errors in the European Union", Contemporary Economic Policy, 31, 795-813.

Beetsma, R. and M. Giuliodori, (2010), "Discretionary Fiscal Policy: Review and Estimates for the EU", CESifo Working Paper 2948.

Beetsma, R., M. Giuliodori and P. Wierts, (2009), "Planning to Cheat: EU fiscal policy in real time", Economic Policy 24, 753-804.

Bernoth, K., A. Hughes-Hallett, and J. Lewis (2008): "Did Fiscal Policy Makers Know What They Were Doing? Reassessing Fiscal Policy with Real Time Data", CEPR Discussion Papers No. 6758.

Caggiano, G., E. Castelnuovo, V. Colombo, and G. Nodari (2015). "Estimating Fiscal Multipliers: News From A Non-Linear World." Economic Journal 125 (584):74676.

Cimadomo, J. (2012), "Fiscal Policy in Real Time", Scandinavian Journal of Economics, Wiley Blackwell, vol. 114(2), 440-465.

Cimadomo, J. (2016), "Real-time data and fiscal policy analysis: A survey of the literature", Journal Economic Surveys, 302-326. 
Corsetti, G., Meier, A. and Muller, G.J. (2012) What Determines Government Spending Multipliers? Economic Policy, 27(72): 521-565.

Croushore, D. (2011): "Frontiers of Real-Time Data Analysis," Journal of Economic Literature, 49, 72-100.

Croushore, D. and C. I. Evans (2006), "Data revisions and the identification of monetary policy shocks", Journal of Monetary Economics, Elsevier, vol. 53(6), pages 1135-1160, September.

Croushore, D., and T. Stark (2001): "A Real-Time Data Set for Macroeconomists", Journal of Econometrics, 105(1), 111-130.

Forni, L. and S. Momigliano (2005), "Cyclical Sensitivity of Fiscal Policies Based on Real-time Data", Applied Economics Quarterly, Volume 50, No. 3.

Forni, M. and L. Gambetti (2016), Government Spending Shocks in Open Economy VARs, Journal of International Economics, 99, 68-84.

Galvao, A and M. Clements (2013), "Real-time Forecasting of Inflation and Output Growth with Autoregressive Models in the Presence of Data Revisions", Journal of Applied Econometrics, 28: 458-477.

Garratt, A., K. Lee, E. Mise and K. Shields (2008), "Real Time Representations of the Output Gap", Review of Economics and Statistics, 90, 4, 792-804.

Garratt, A., K.C. Lee, E. Mise and K. Shields (2009), "Real Time Representations of the UK Output Gap in the Presence of Model Uncertainty", International Journal of Forecasting, 25, 81-102.

Golinelli, R., and S. Momigliano (2006), "Real-Time Determinants of Fiscal Policies in the Euro Area," Journal of Policy Modeling, 28(9), 943-964.

Holm-Hadulla, F., S. Hauptmeier, and P. Rother (2012), "The Impact of Numerical Expenditure Rules on Budgetary Discipline over the Cycle", Applied Economics, Vol. 44, Issue 25, 3287-3296. 
Jonung, L. and M. Larch (2006) "Improving fiscal policy in the EU: the case for independent forecasts", Economic Policy, 21, 492-534.

von Kalckreuth, U. and G.B. Wolff (2011) "Identifying discretinary fiscal policy reactions with real-time data", Journal of Money, Credit and Banking, 43, 12711285.

Larch M. and M. Salto (2005) "Fiscal rules, inertia and discretionary fiscal policy", Applied Economics, 37:10

Lee, K. C., J. Morley, K. Ong and K. Shields (2018), "Measuring the Fiscal Multiplier when Plans Take Time to Implement", Working Paper.

Lee, K. C., J. Morley, K. Shields, and S. Tan (2015), Australian Fiscal Real-Time Database: A $\quad$ Users available at http://www.economics.unimelb.edu.au/RTAustralianMacroDatabase.

Li, S. M. and A. H. Spencer (2015), "Effectiveness of the Australian Fiscal Stimulus Package: A DSGE Analysis", The Economic Record, Vol. 92, Issue 296, 94-120.

Makin, A.J. and P.K. Narayan (2005), How Potent is Fiscal Policy in Australia?, Economic Papers, 30, 377-385.

Orphanides, A. and S. van Norden (2002), "The Unreliability of Output Gap Estimates in Real Time", Review of Economics and Statistics, 84, 4, 569-83.

Ramey, V. A. (2016), "Macroeconomic Shocks and Their Propagation", Handbook of Macroeconomics, 2, 71-162.

Ramey, V. and S. Zubairy (2018), "Government Spending Multipliers in Good Times and in Bad: Evidence from U.S. Historical Data", Journal of Political Economy, $126(2), 850-901$.

Ricco, G., (2016) "A new identification of fiscal shocks based on the information flow", ECB Working Paper 1813. 
Figure 1a: Nominal Outlays, Investment and Transfers (\% of GDP)

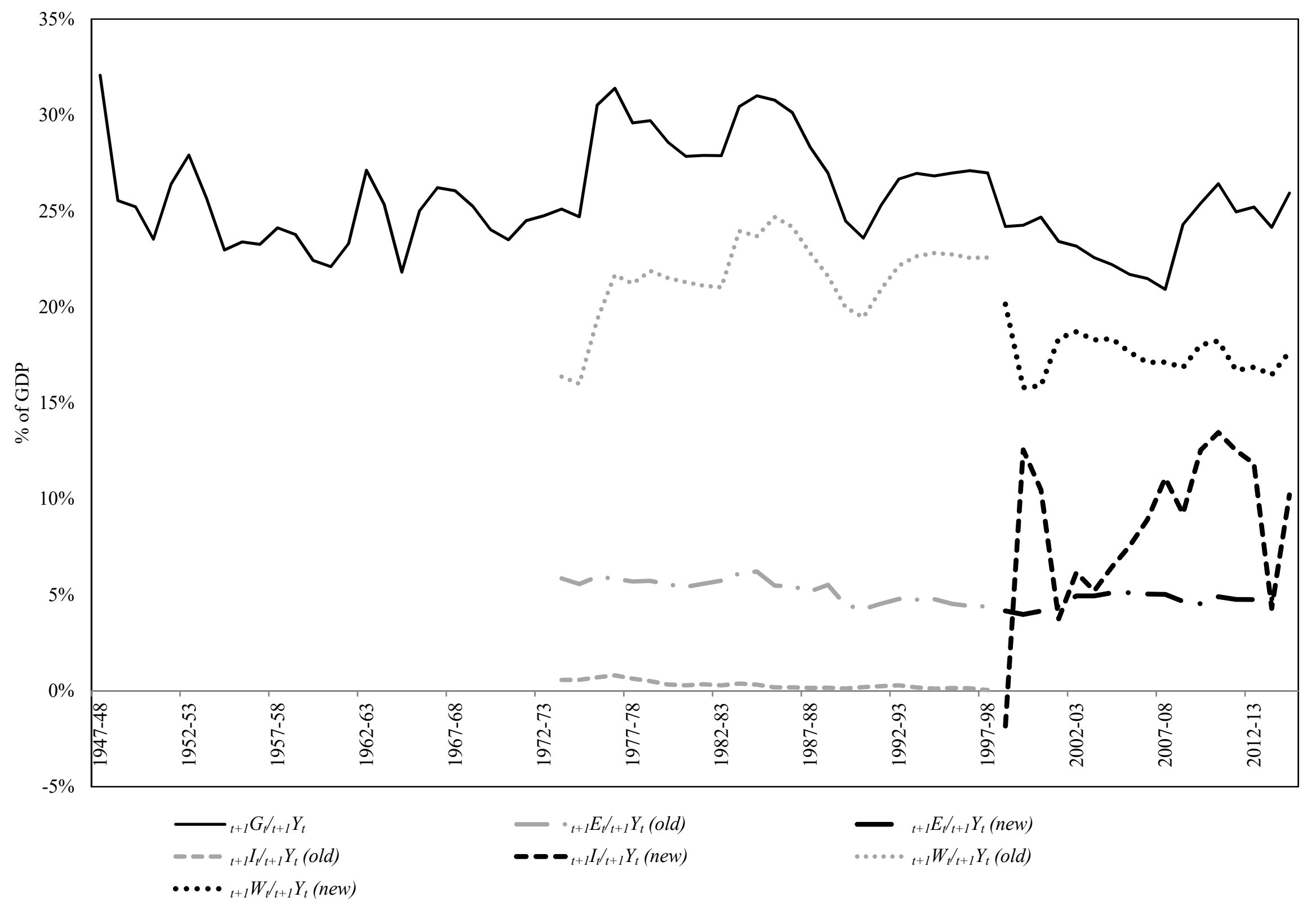


Figure 1b: Nominal Receipts, Indirect and Direct Taxation (\% of GDP)

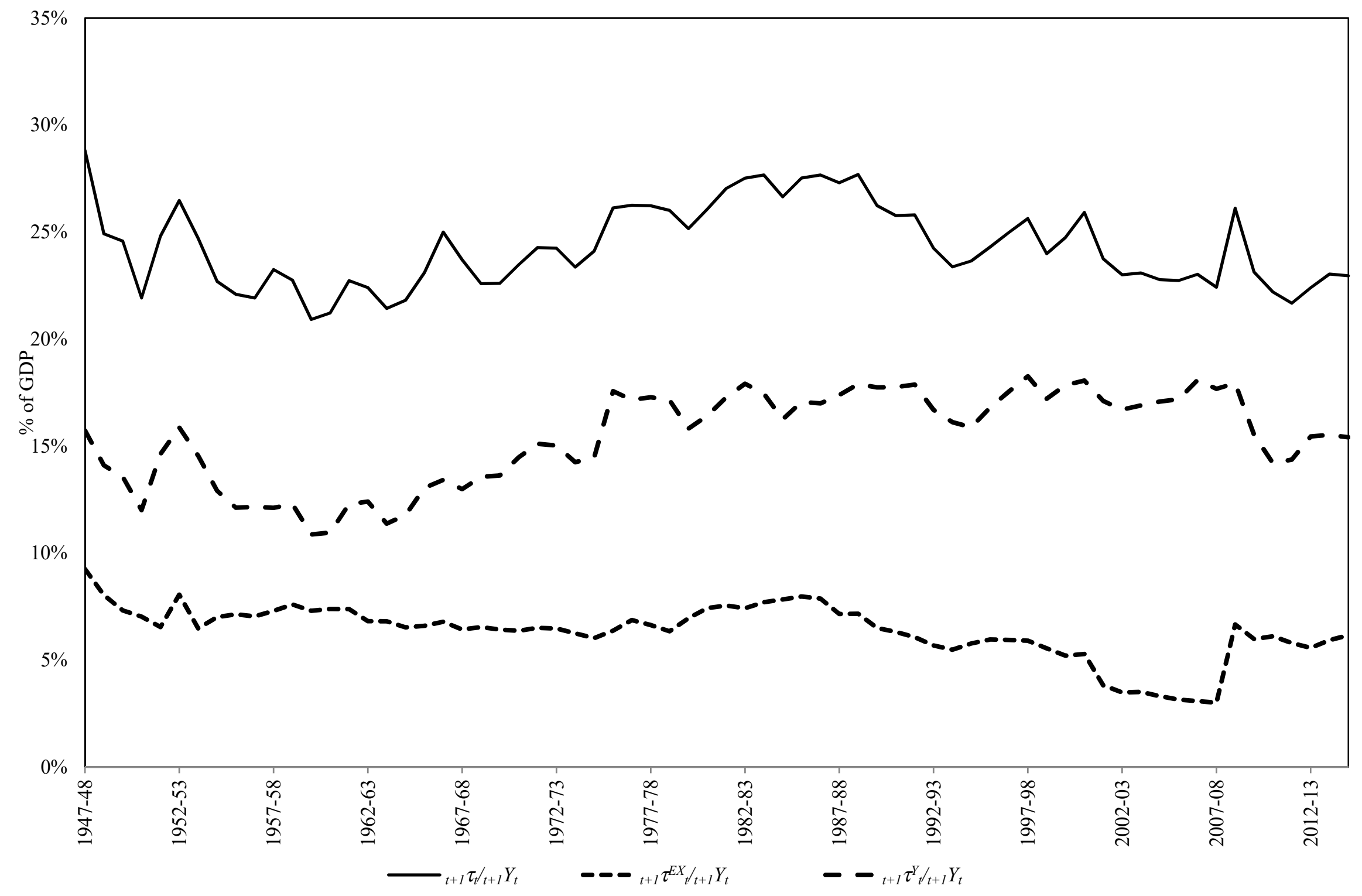


Figure 2a: Reported Surplus at 10 year Intervals from Vintages 1948-49 to 2015-16

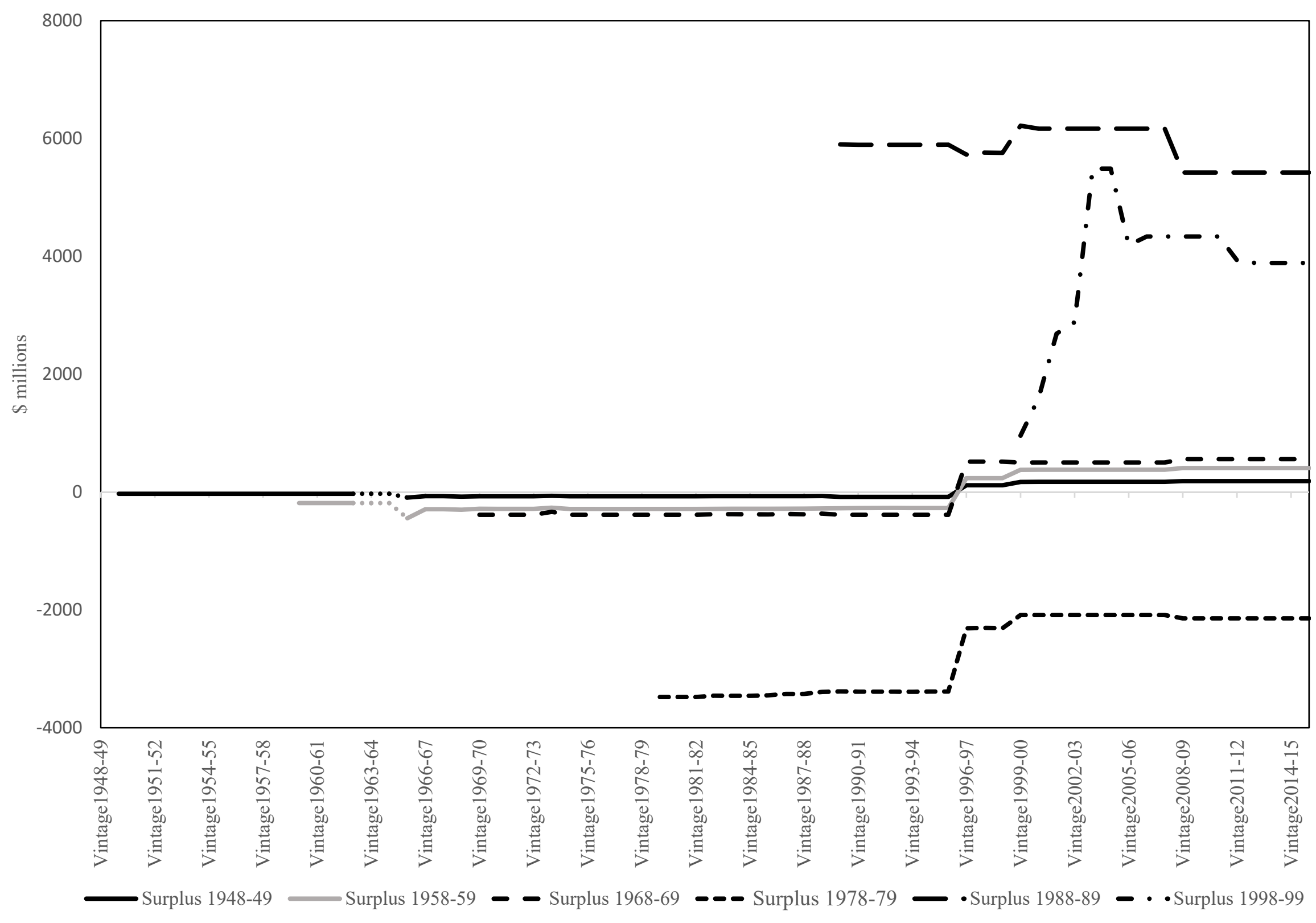


Figure 2b: Reported Surplus as a Percentage of GDP at 10 year Intervals from

Vintages $1948-49$ to $2015-16$

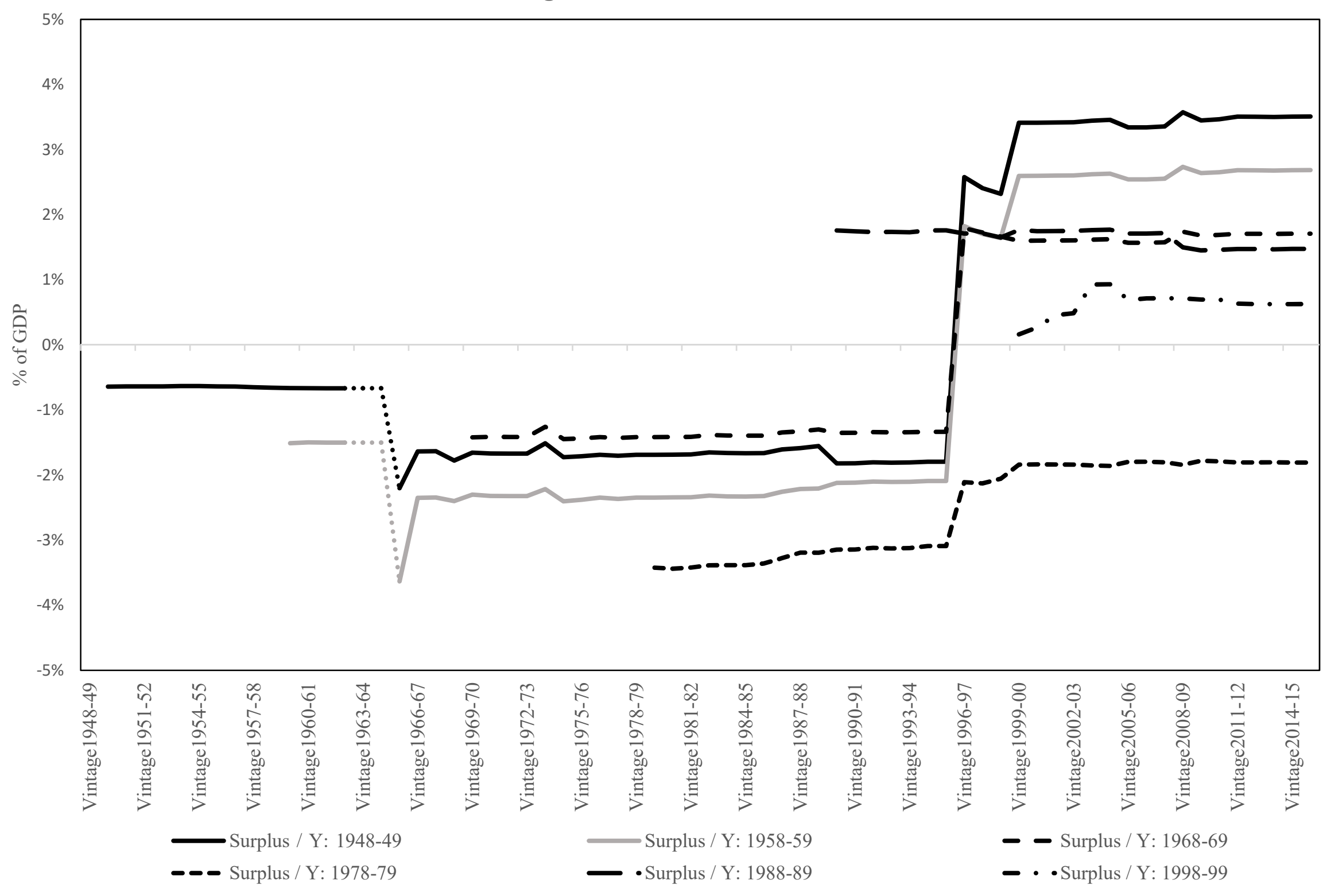


Figure 3a: Real Time Real Government Spending Releases for Australia: 1946 - 2015

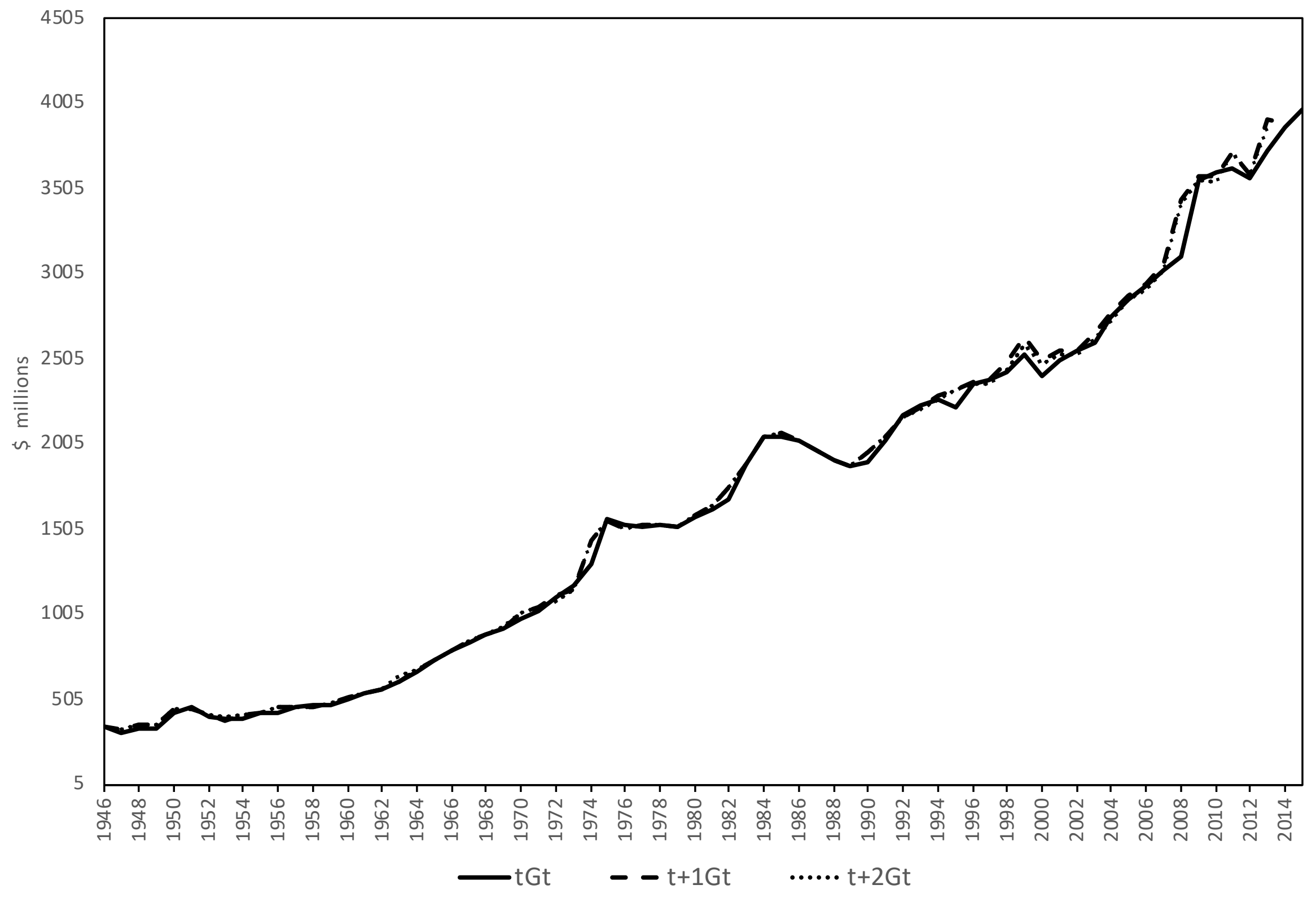


Figure 3b: Real Time Real Government Receipt Releases for Australia: 1946 - 2015

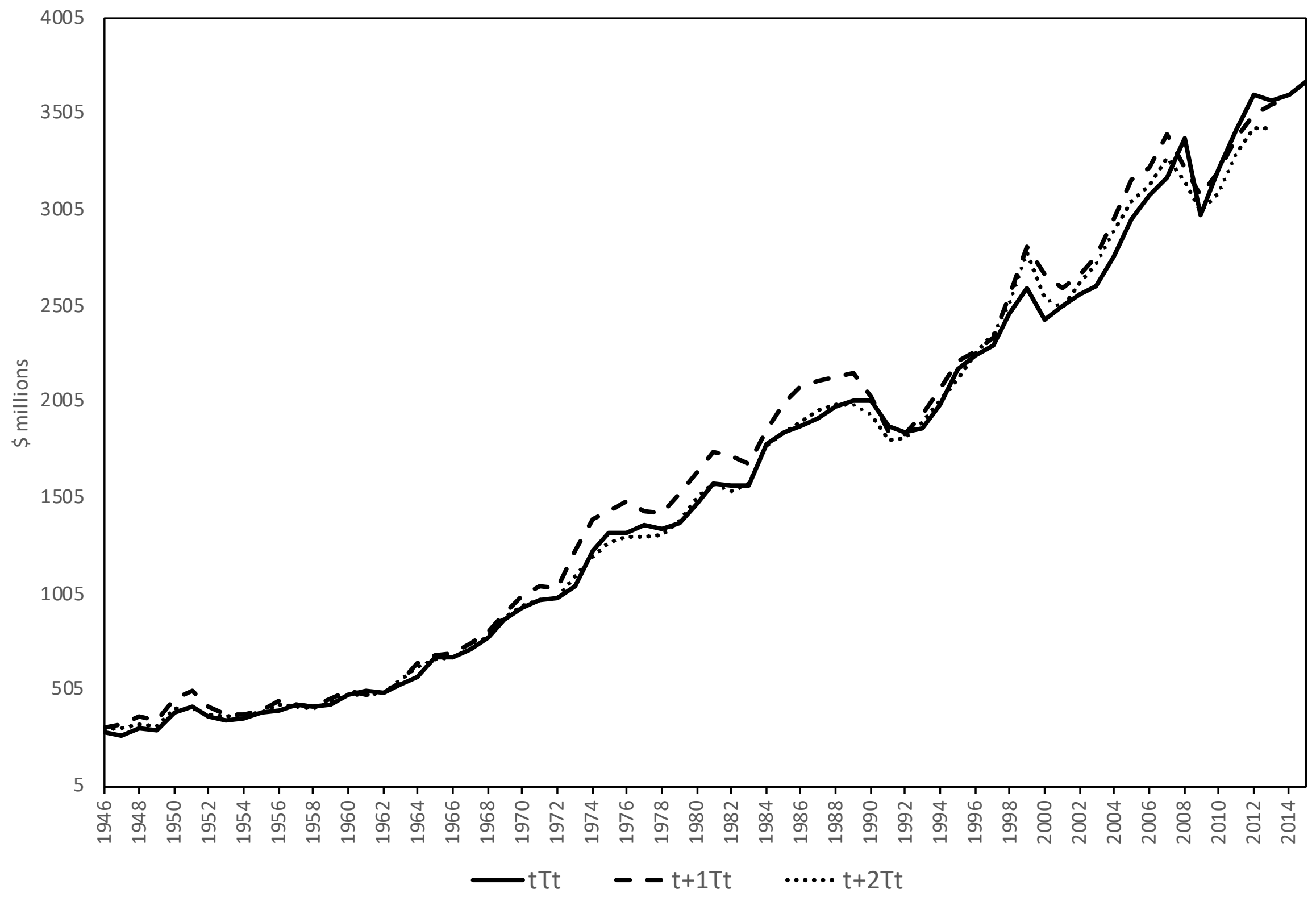


Figure 3c: Real Time Real Primary Balance Series for Australia: 1946 - 2015

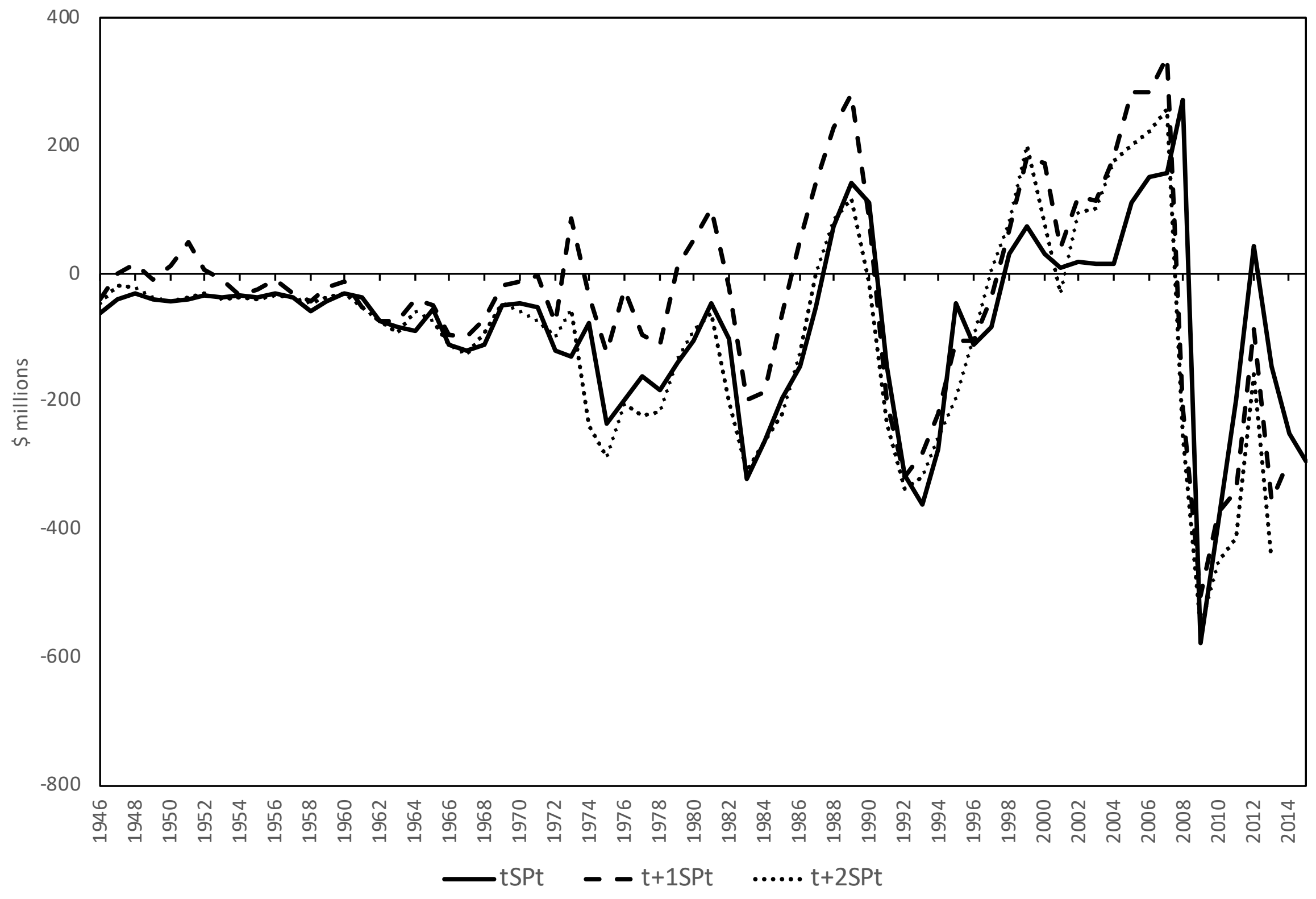


Figure 4: Ratios of Actual Spending to Output $\left({ }_{t} G_{t-1} / t Y_{t-1}\right)$ and Actual Receipts to Output $\left({ }_{t} \tau_{\mathrm{t}-1} / \mathrm{t}_{\mathrm{t}-1}\right)$

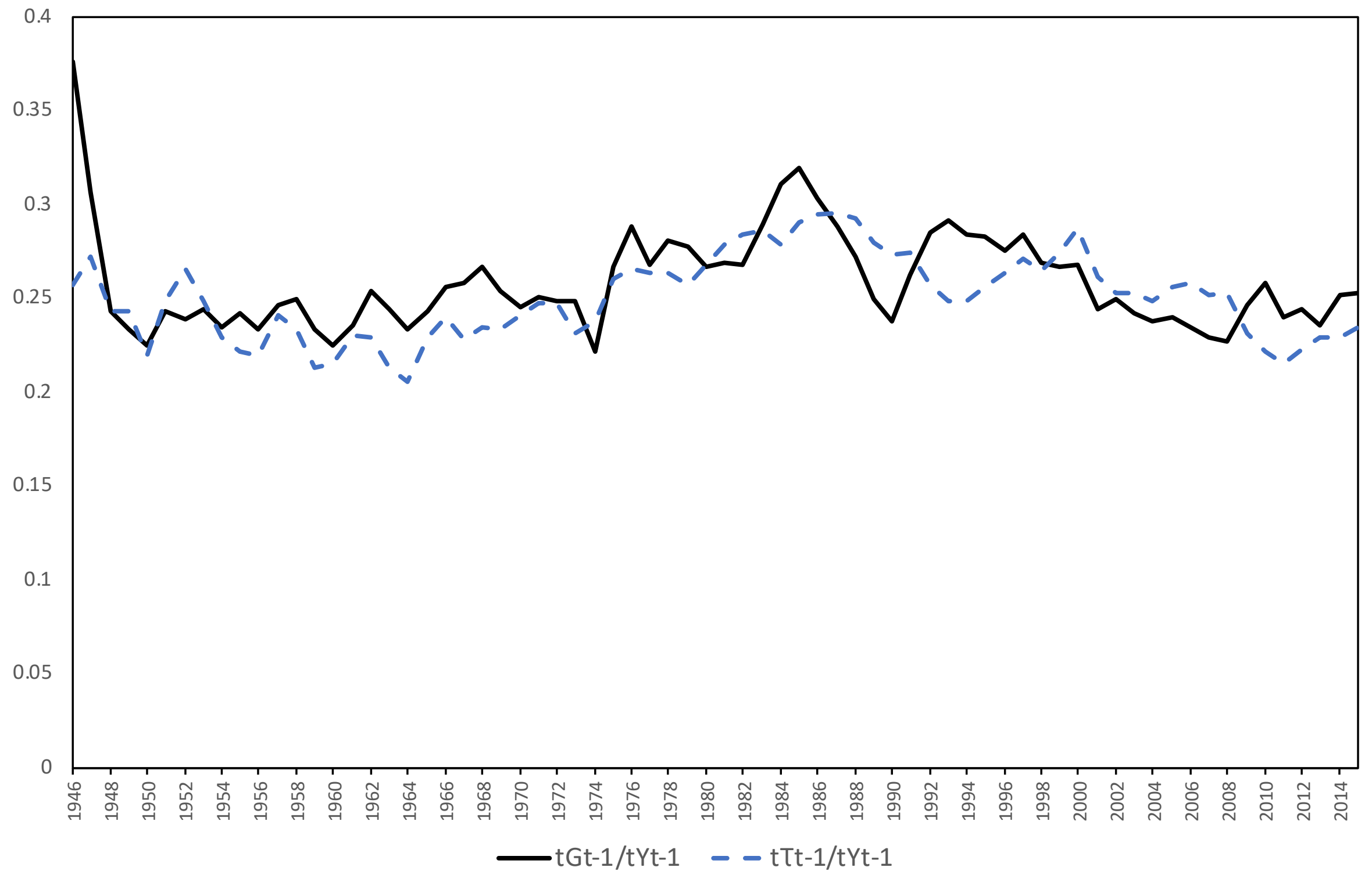


Figure 5a: Generalised Impulse Response of a Unit ${ }_{t} g_{t-1}(' e ')$ Shock

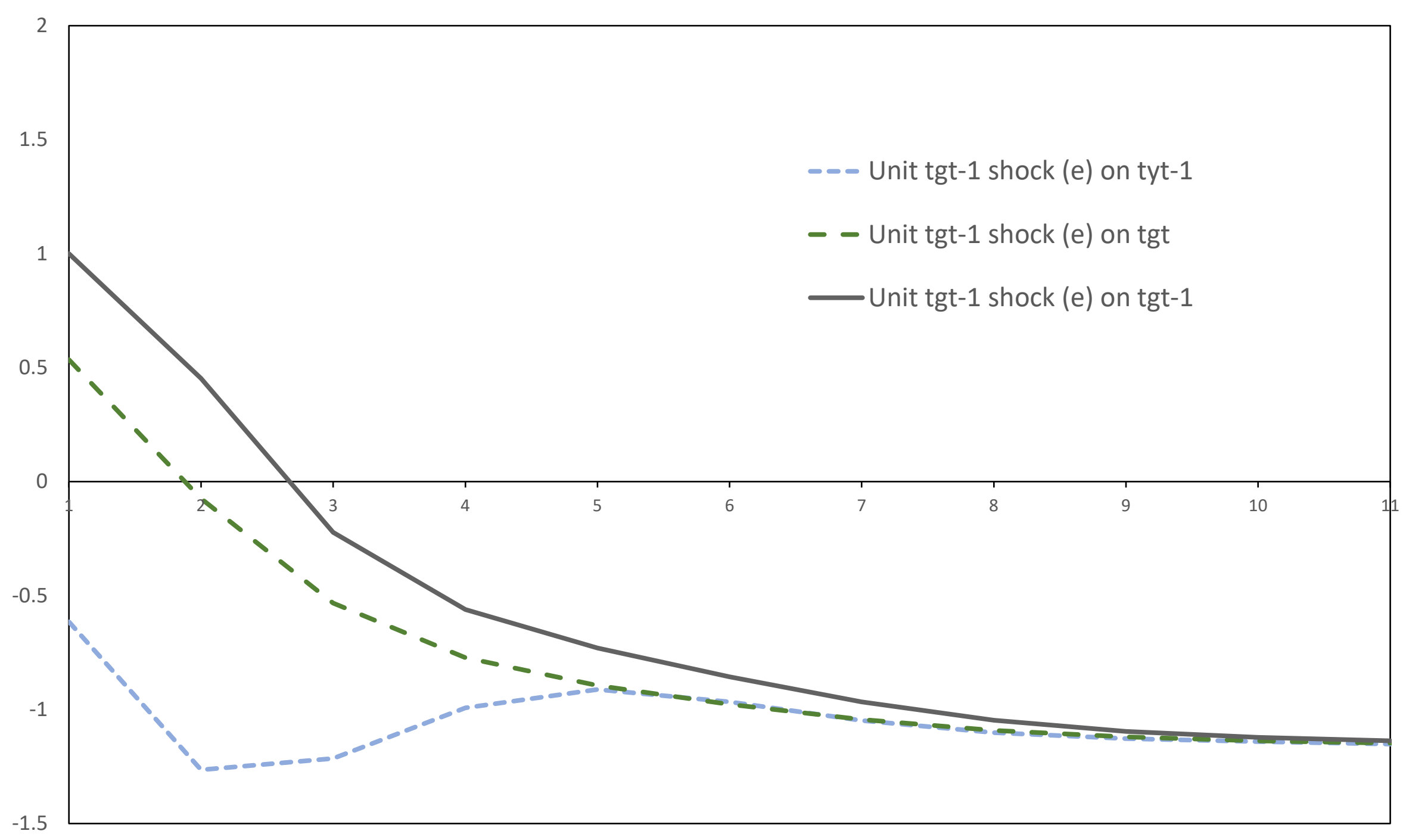


Figure 5b: Generalised Impulse Response of a Unit ('e-tilde') ${ }_{t+1} g_{t}$ Shock

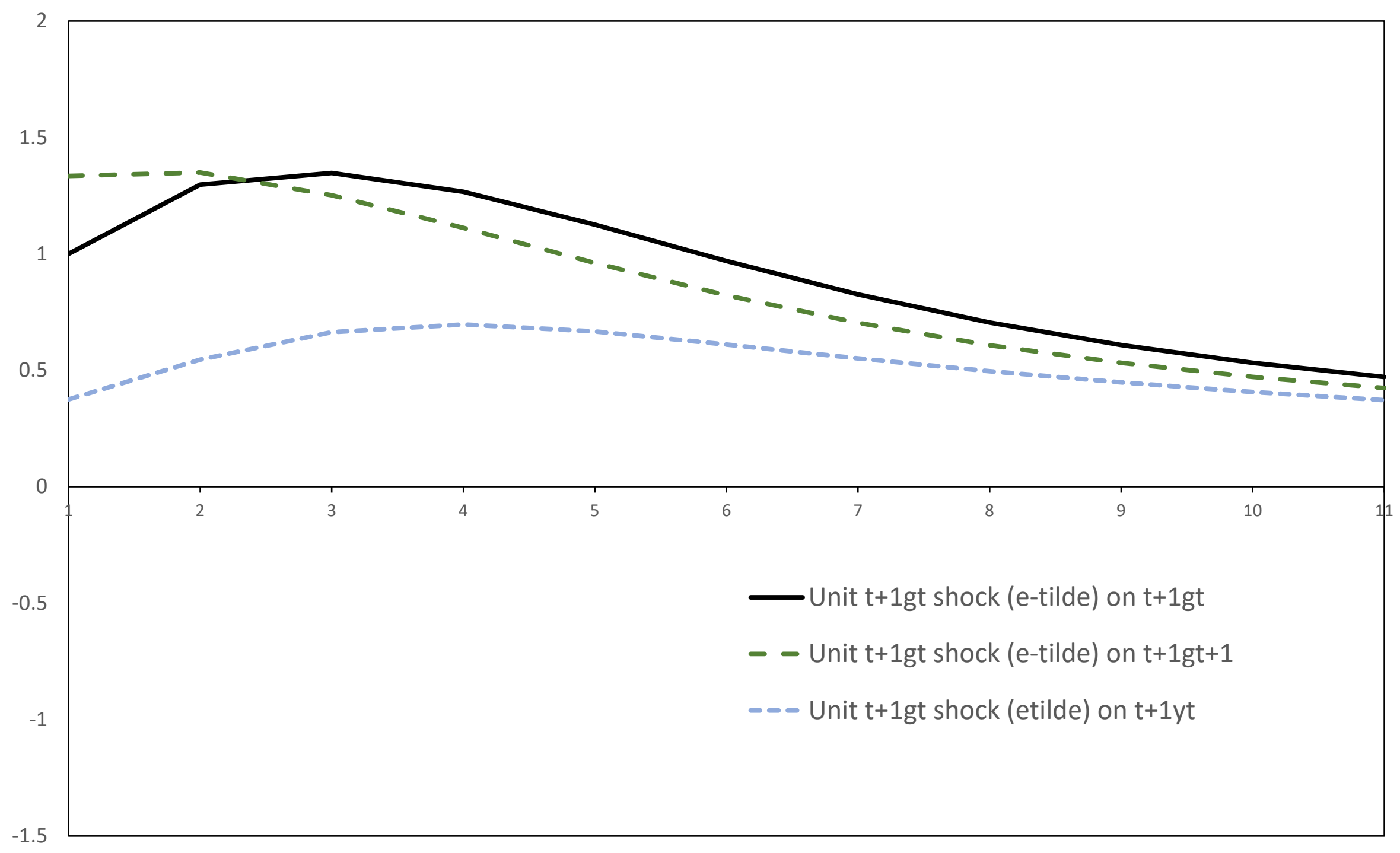


Figure 6: Spending Implementation Shocks $\left(v_{1 t}\right)$ and Spending Initiatives Shocks ( $\left.v_{3 t}\right)$ (with 1975, 2009 dummies)

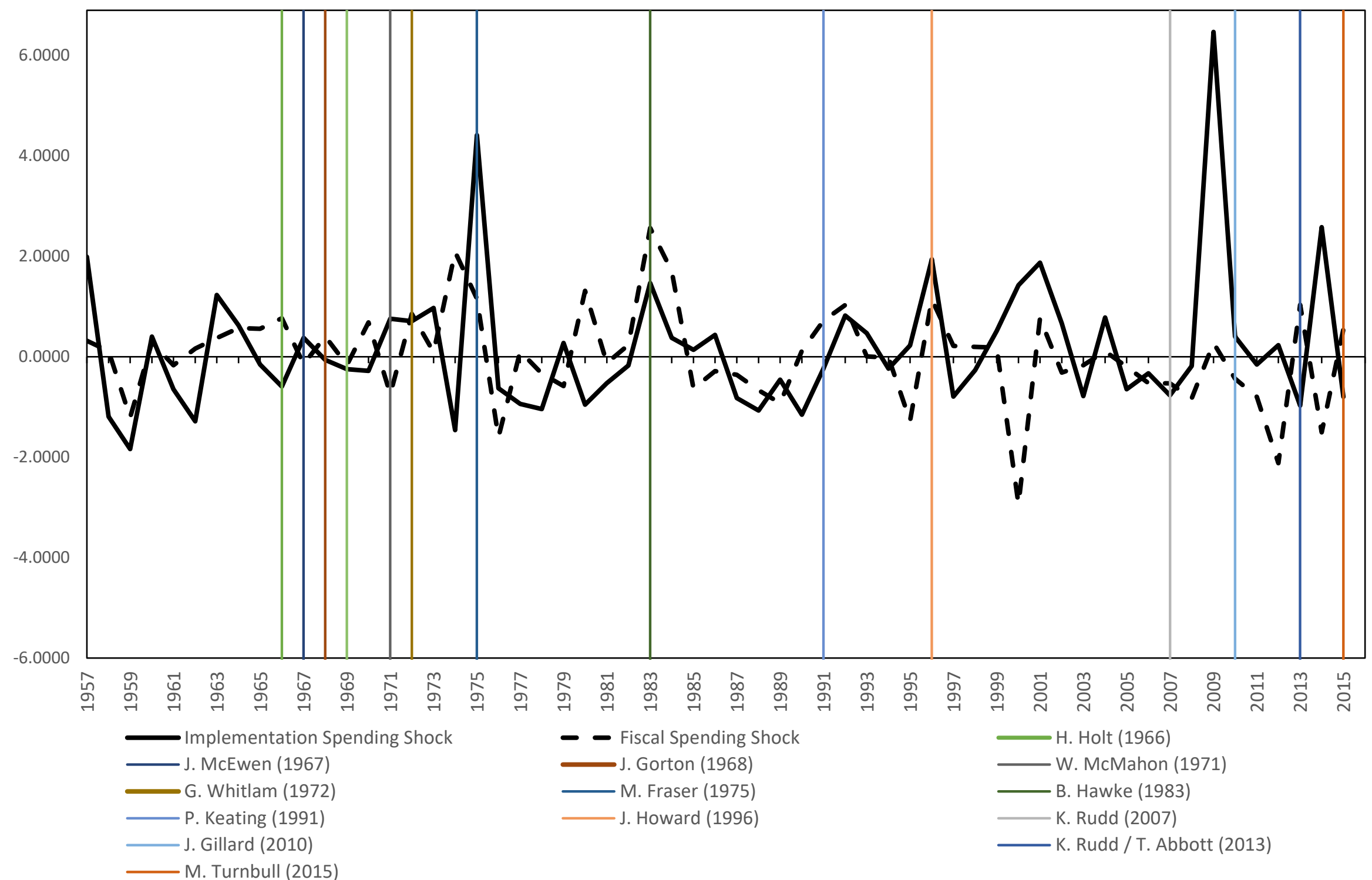


Figure 7: Orthogonal Impulse Reponse Functions:

Dynamic Effects of 'Spending Implementation Shocks' $\left(v_{1 t}\right)$ and 'Spending Initiative

Shocks' $\left(v_{3 t}\right)$ on Forecasted Actual Spending at Time $t,{ }_{t+1} g_{t}$

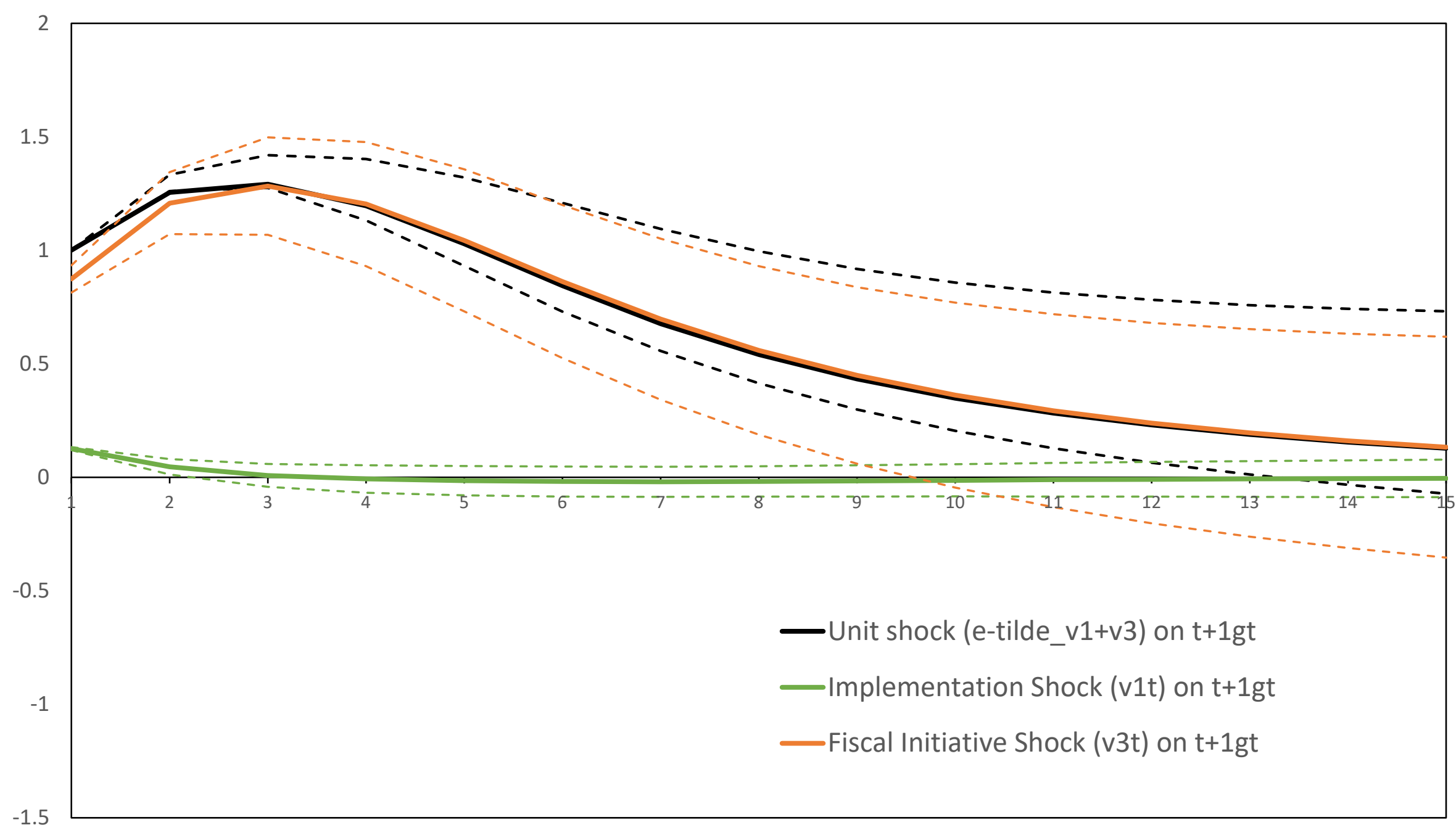


Figure 8: Orthogonal Impulse Response Functions:

Dynamic Effects of 'Spending Implementation Shocks' $\left(v_{1 t}\right)$ and 'Spending Initiative Shocks' $\left(v_{3 t}\right)$ to Forecasted Actual Spending, ${ }_{t+1} g_{t}$ and Forecasted Actual Output, ${ }_{t+1} y_{t}$, at time $t$

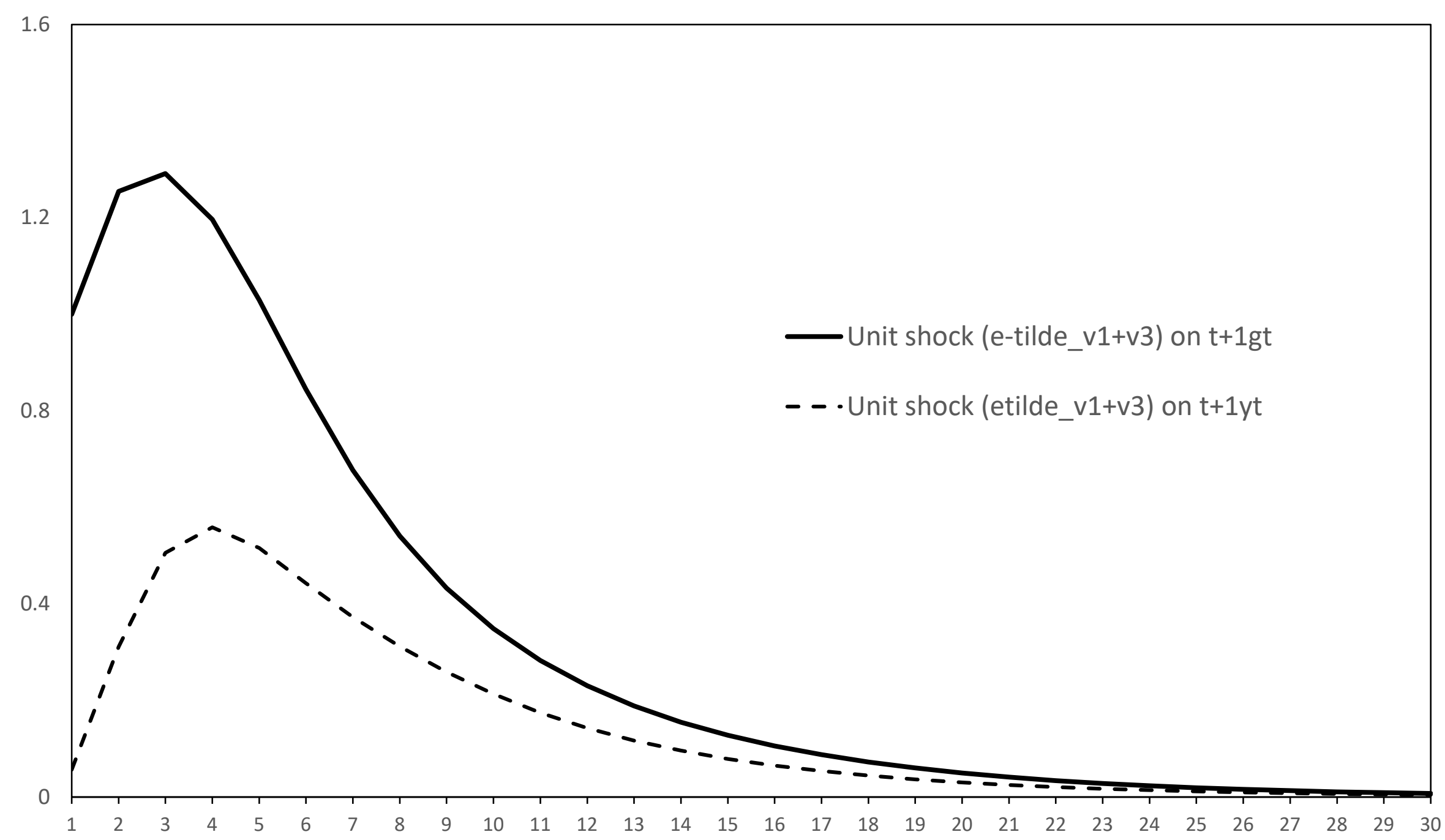


Figure 9: Total Fiscal Multiplier and Fiscal Initiatives Multiplier

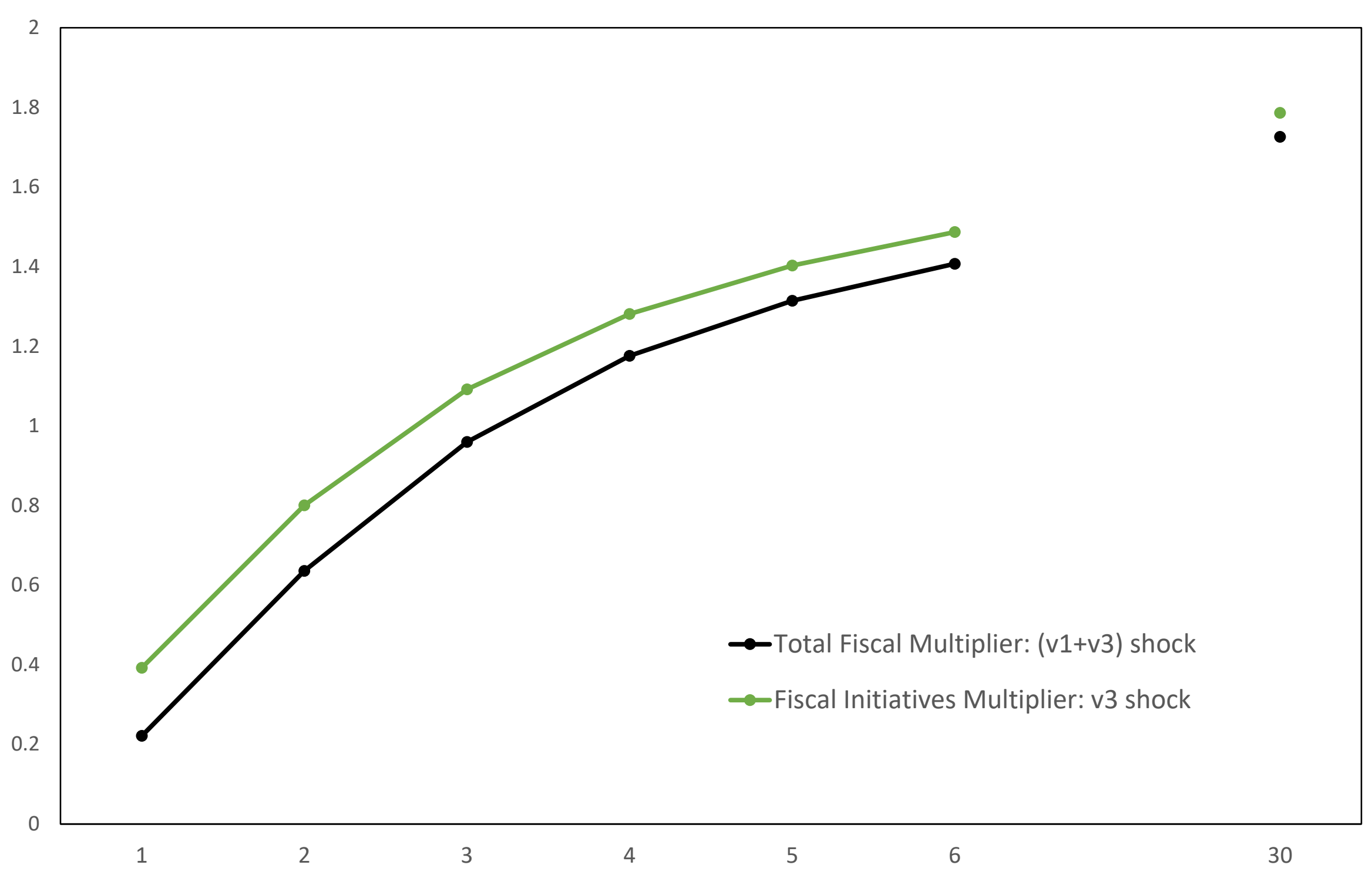


Appendix

Table A1 Contents of the Australian Real-Time Fiscal Dataset

\begin{tabular}{|c|c|c|c|c|c|}
\hline No & Name & & $\begin{array}{l}\text { Notation in } \\
\text { Manual }\end{array}$ & $\begin{array}{l}\text { First } \\
\text { Vintage } \\
\text { Date }\end{array}$ & $\begin{array}{l}\text { Last } \\
\text { Vintage } \\
\text { Date }\end{array}$ \\
\hline $\boldsymbol{A}$ & Revenue & & & & \\
\hline 1 & & Receipts & REV & 1901-02 & 2015-16 \\
\hline 2 & & Income Tax (Direct) & DTAX & $1901-02$ & 2015-16 \\
\hline 3 & & Expenditure Tax (Indirect) & IDTAX & $1901-02$ & $2015-16$ \\
\hline $\bar{B}$ & Expenditure & & & & \\
\hline 4 & & Outlays & OUT & 1901-02 & 2015-16 \\
\hline 5 & & Spending on Goods and Services & GSEXP & 1973-74 & 2015-16 \\
\hline 6 & & Health & OUTHEA & $1946-47$ & 2015-16 \\
\hline 7 & & Education & OUTEDU & 1967-68 & 2015-16 \\
\hline 8 & & Defence & OUTDEF & $1947-48$ & 2015-16 \\
\hline 9 & & Spending on Capital Goods & CAPEXP & 1973-74 & 2015-16 \\
\hline 10 & & Transfers & TPAY & 1973-74 & 2015-16 \\
\hline 11 & & Welfare & OUTSSEC & $1946-47$ & 2015-16 \\
\hline 12 & & Pensions & OUTPEN & $1946-47$ & 2015-16 \\
\hline 13 & & Debt Interest Paid & PDI & $1962-63$ & 2015-16 \\
\hline$C$ & Balance & & & & \\
\hline 14 & & Cash Balance & BAL & $1962-63$ & 2015-16 \\
\hline 15 & & Fiscal Balance & FBAL & 1999-00 & 2015-16 \\
\hline D & Debt & & & & \\
\hline 16 & & Gross Debt & GDEBT & $1925-26$ & 2013-14 \\
\hline 17 & & Public Debt & PDEBT & 1912-13 & 2015-16 \\
\hline 18 & & Net Debt & NDEBT & 1994-95 & 2015-16 \\
\hline 19 & & Commonwealth Interest Liability & COMINTLIAB & 1932-33 & 1989-90 \\
\hline 20 & & Total Interest Liability & TOTINTLIAB & 1932-33 & 2015-16 \\
\hline 21 & & Net Interest Outlays & NIO & $2002-03$ & $2015-16$ \\
\hline$E$ & Wealth & & & & \\
\hline 22 & & Net Worth & NWORTH & 1999-00 & 2015-16 \\
\hline 23 & & Net Financial Worth & NFW & 2000-01 & 2015-16 \\
\hline 24 & & Net Operating Balance & NOB & 1999-00 & 2015-16 \\
\hline
\end{tabular}




\section{University Library}

\section{- M M N E R VA A gateway to Melbourne's research publications}

Minerva Access is the Institutional Repository of The University of Melbourne

Author/s:

Lee, K;Morley, J;Shields, K;Tan, MS-L

Title:

The Australian Real-Time Fiscal Database: An Overview with Illustrations of Its Use in Analysing Fiscal Policy

Date:

2020-03-01

\section{Citation:}

Lee, K., Morley, J., Shields, K. \& Tan, M. S. -L. (2020). The Australian Real-Time Fiscal Database: An Overview with Illustrations of Its Use in Analysing Fiscal Policy. The Economic Record, 96 (312), pp.87-106. https://doi.org/10.1111/1475-4932.12509.

Persistent Link:

http://hdl.handle.net/11343/241682 